\title{
Flexor carpi radialis tendon ultrasound pictorial essay
}

\author{
Dien Hung Luong • Jay Smith • Stefano Bianchi
}

Received: 6 November 2013 /Revised: 2 January 2014 / Accepted: 5 February 2014 /Published online: 23 March 2014

(C) ISS 2014

\begin{abstract}
Disorders of the flexor carpi radialis tendon (FCRt) are often missed even though they are a relatively frequent cause of volar radial wrist pain. They can manifest as tenosynovitis, tendinopathy, synovial sheath cysts with or without scaphoid-trapezoid-trapezium (STT) joint pathology, and partial or complete rupture. Because FCRt disorders often present with non-specific symptoms and a non-diagnostic clinical examination, imaging is often necessary for accurate evaluation and therapeutic planning. Conventional radiography provides good visualization of the neighboring bones and joints, as well as rare intratendinous calcifications. MRI enables evaluation of the FCRt and adjacent anatomical structures with excellent tissue resolution. In comparison, ultrasound (US) evaluation of the FCRt is less commonly described in the radiology literature, despite its affordability, exquisite soft tissue resolution, and the advantages of quick, dynamic
\end{abstract}

D. H. Luong $(\bowtie)$

Department of PM\&R, Montreal University, Montreal, Canada

e-mail: dh.luong@umontreal.ca

J. Smith

Department of PM\&R, Mayo Clinic College of Medicine, Mayo

Clinic, Rochester, MN, USA

e-mail: smith.jay@mayo.edu

J. Smith

Department of Radiology, Mayo Clinic College of Medicine, Mayo

Clinic, Rochester, MN, USA

J. Smith

Department of Anatomy, Mayo Clinic College of Medicine, Mayo

Clinic, Rochester, MN, USA

D. H. Luong $\cdot \mathrm{S}$. Bianchi

CIM SA, Cabinet d'Imagerie Médical, route de Malagnou 40A,

1208 Geneva, Switzerland

S. Bianchi

e-mail: stefanobianchi@bluewin.ch diagnostic imaging. This pictorial essay describes and demonstrates the normal anatomy of the FCRt, its US examination technique and normal US appearance, and US findings of clinically relevant FCRt disorders.

Keywords Flexor carpi radialis tendon · Ultrasound · Tendinopathy $\cdot$ Wrist injuries

\section{Introduction}

Disorders of the flexor carpi radialis tendon (FCRt) are still often missed even though they are a relatively frequent cause of volar radial wrist pain. They can manifest as tenosynovitis, tendinopathy, synovial sheath cysts with or without scaphoidtrapezoid-trapezium (STT) joint pathology, and partial or complete rupture [1]. Microtraumatic tendinopathies are closely associated with osteoarthritis of the STT joint, a frequent problem in the elderly population $[1,2]$. Inflammatory disorders such as rheumatoid arthritis (RA) can spread to the synovial sheath surrounding the FCRt. Pathologies of the FCRt can also be associated with other synovial proliferative diseases such as pigmented villonodular synovitis (PVNS) [3]. Finally, the FCRt, like any other tendons, can be prone to overuse, trauma, intratendinous calcification or iatrogenic lesions [4-7].

Because FCRt disorders often present with non-specific symptoms and a non-diagnostic clinical examination, imaging is often necessary for accurate evaluation and therapeutic planning. Conventional radiography provides good visualization of the neighboring bones and joints, as well as rare intratendinous calcifications. MRI enables evaluation of the FCRt and adjacent anatomical structures with excellent tissue resolution $[1,8]$. In comparison, ultrasound (US) evaluation of the FCRt is less commonly described in the radiology literature, despite its affordability, exquisite soft tissue resolution, 


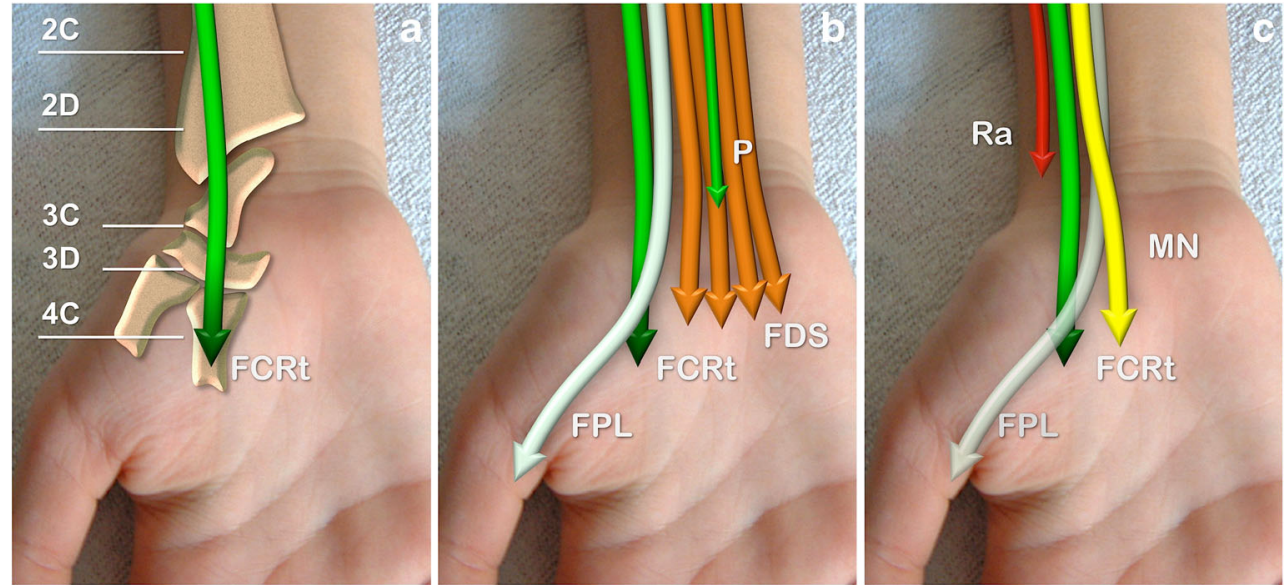

Fig. 1 Surface anatomy of the flexor carpi radialis tendon (FCRt) and adjacent structures. a Relations of FCRt with the bones. The FCRt overlies the distal radius, scaphoid, and STT joint. It points dorsally to become deep and insert mainly into the base of the second metacarpal. The lines $2 \mathrm{C}$ to $4 \mathrm{C}$ indicate the level where the Figs. $2 \mathrm{c}$ to $4 \mathrm{c}$ were obtained. b Relations of FCRt with the adjacent tendons. At the level of the carpometacarpal joint the flexor pollicis longus (FPL) cross the FCRt by running superficially to it. The smaller palmaris longus $(\mathrm{P})$ and the flexor digitorum superficialis tendons (FDS) lie ulnarly. c Relations of FCRt with the adjacent nerves and arteries. The median nerve lies ulnar to the FCRt and FPL. Ra radial artery

diagnostic and therapeutic injections when clinically indicated. and the advantages of quick, dynamic diagnostic imaging. Moreover, US is well tolerated by the patient and facilitates

\section{indicated.}
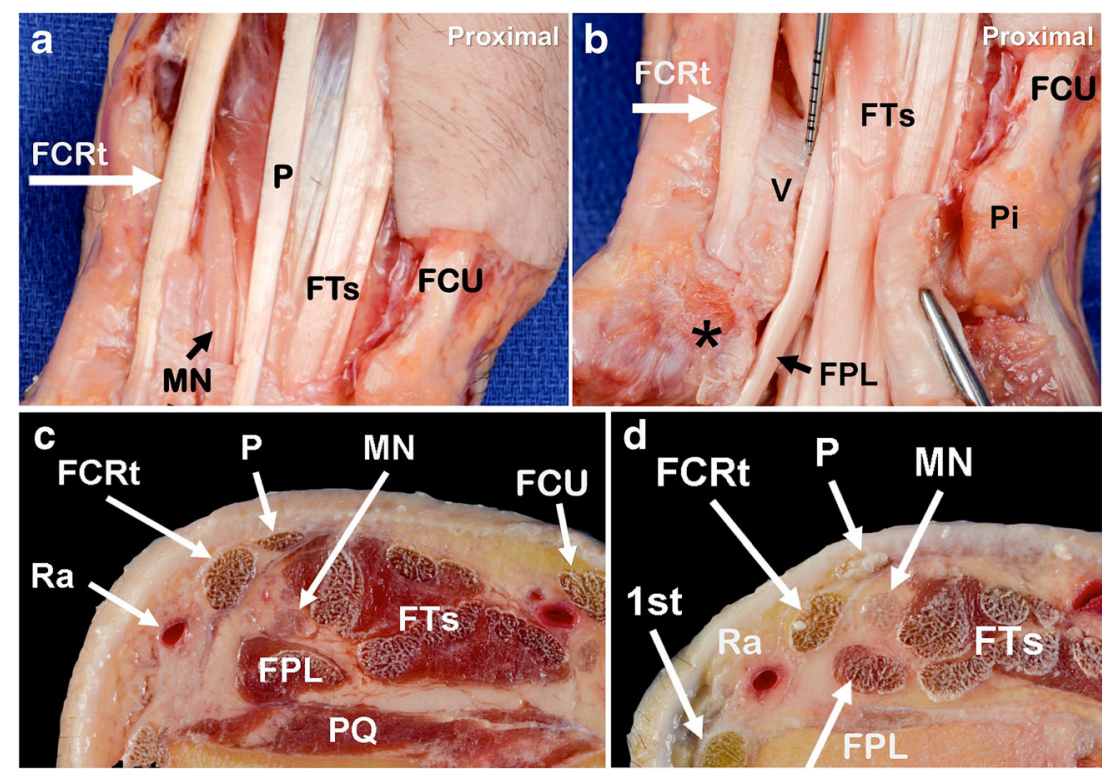

Fig. 2 Anatomy of the flexor carpi radialis tendon (FCRt) in the distal forearm and proximal wrist. Anatomic dissections. a Distal forearm. The FCRt runs in the radial aspect of the wrist, radial to the median nerve (MN). $P$ palmaris longus, $F T s$ flexor tendons, $F C U$ flexor carpi ulnaris. b Proximal wrist. The flexor retinaculum has been incised at its radial aspect and reflected ulnarly (forceps). The median nerve has been removed, exposing the flexor tendons (FTs) and flexor pollicis longus (FPL) within the carpal tunnel. The FCRt has been exposed as it courses over the scaphoid by removing a portion of the retinacular septum. The vertical component of the retinacular septum, which forms the ulnar wall of the FCRt's fibro-osseous tunnel remains intact (V). The septum separates the FCRt from the carpal tunnel. More distally, the FCRt remains covered by the retinaculum and the overhanging tubercle of the trapezium (asterisk), which in this specimen forms an osseous roof over the FCRt. $P i$ pisiform, $F C U$ flexor carpi ulnaris. c-d Anatomic cross-sectional images. c Distal forearm. d Proximal wrist. Note the proximity of the FCRt to the radial artery (Ra), palmaris longus (P), and flexor pollicis longus (FPL). $M N$ median nerve, $F T s$ flexor tendons, $F C U$ flexor carpi ulnaris, $1 s t$ first dorsal extensor compartment, $P Q$ pronator quadratus. Left radial, Right ulnar 

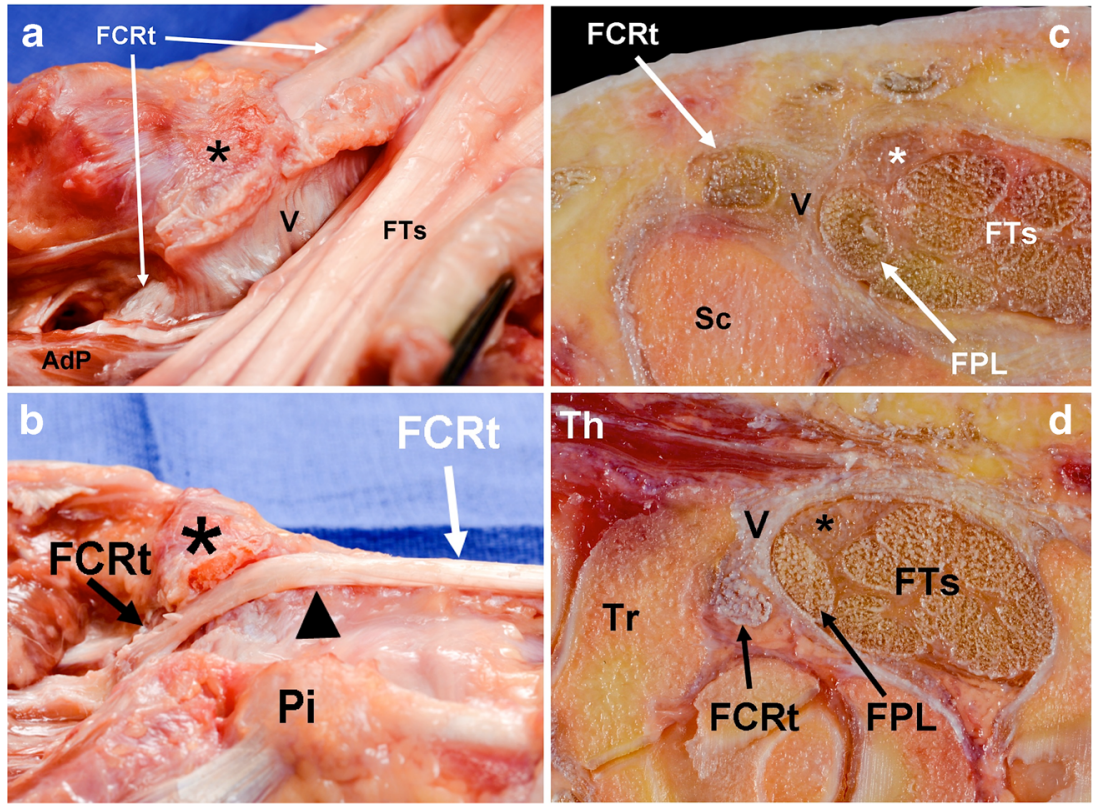

Fig. 3 Anatomy of the flexor carpi radialis tendon (FCRt) in the wrist. ab Anatomic dissection demonstrating the passage of the FCRt through its fibro-osseous canal. a The view is from the palmoulnar aspect of the wrist. The flexor retinaculum has been reflected ulnarly and the flexor tendons (FTs) retracted ulnarly to expose the vertical retinacular septum (V), which forms the ulnar wall of the FCRt's fibro-osseous tunnel. The tubercle of the trapezium is hypertrophied in this specimen and forms an osseous roof over the FCRt (asterisk). Distal to the tunnel, the FCRt emerges in a deep (i.e., dorsal) position in its way to its insertion on the second metacarpal (obscured by the proximal edge of the adductor pollicis muscle, AdP). b The FCRt passes superficial to the scaphoid tubercle (black arrowhead), and then angles dorsally to enter a fibroosseous canal formed by the trapezium and the vertical retinacular septum. The vertical retinacular septum has been removed to expose the

This pictorial essay describes and demonstrates the normal anatomy of the FCRt, its US examination technique and normal US appearance, and US findings of clinically relevant FCRt disorders.

\section{Anatomy}

The flexor carpi radialis muscle (FCRm) originates from the humerus epitrochlea and is located in the anterior forearm compartment. It is a bipennate and biarticular muscle whose myo-tendinous junction begins approximately $15 \mathrm{~cm}$ proximal to the radiocarpal joint. The FCRt measures approximately $7 \mathrm{~cm}$ in length [2]. It is initially flattened, adopts an ellipsoidal shape within its middle region, and becomes flattened again prior to its insertion. The FCRt descends deep to the antebrachial fascia and courses superficial to the flexor pollicis longus (FPL) (Fig. 1). The FCRt fibers rotate approximately 180 degrees on themselves, from proximal to distal, clockwise in the right forearm and counter-

FCRt as it courses under the osseous trapezius roof (asterisk). Distally, the FCRt continues to move dorsally towards its insertion on the second metacarpal. $P i$ pisiform. c-d. Anatomic cross-sectional images. c Note the FCRt passing over the scaphoid $(\mathrm{Sc})$ in the proximal wrist. The vertical retinacular septum (V) forms the palmar and ulnar border of the FCRt's proximal fibro-osseous tunnel. This last retinaculum separates the FCRt from the carpal tunnel. d Note the close relationship between the flexor carpi radialis tendon (FCRt) and the surrounding structures forming its distal fibro-osseous tunnel - the trapezium (Tr) radial and palmar, the vertical retinacular septum (V) palmar and ulnar, and the carpal tunnel ulnar. FPL flexor pollicis longus, FTs flexor tendons. Th thenar musculature, asterisk median nerve, FTs flexor tendons. Left radial, Right ulnar

clockwise in the left [9]. Proximally, the sheath of the FCRt consists only of a thin peritenon [2].

The distal radius is a critical area in orthopedic surgery as it is the site of plate fixation for distal radius fractures. In this region, the palmar cutaneous branch of the median nerve, the palmaris longus tendon, and the median nerve border the FCRt ulnarly. More radial, the FCRt is bordered by the FPL tendon located at depth, followed by the radial artery, brachioradialis tendon, superficial radial nerve and the wrist first extensor compartment $[8,10]$ (Fig. 2).

More distally, at the wrist level, the FCRt courses inside a fibro-osseous tunnel (Fig. 3). Proximally, this tunnel is formed by the scaphoid, the flexor retinaculum, and a vertical retinacular septum originating from the distal pole of the scaphoid and the trapezoid and inserting into the flexor retinaculum. More distally, this tunnel is formed by the trapezium body and tubercle, the flexor retinaculum, and the vertical retinacular septum [2]. This septum separates the FCRt from the carpal tunnel. The distal fibro-osseous tunnel is narrower and the FCRt occupies approximately 

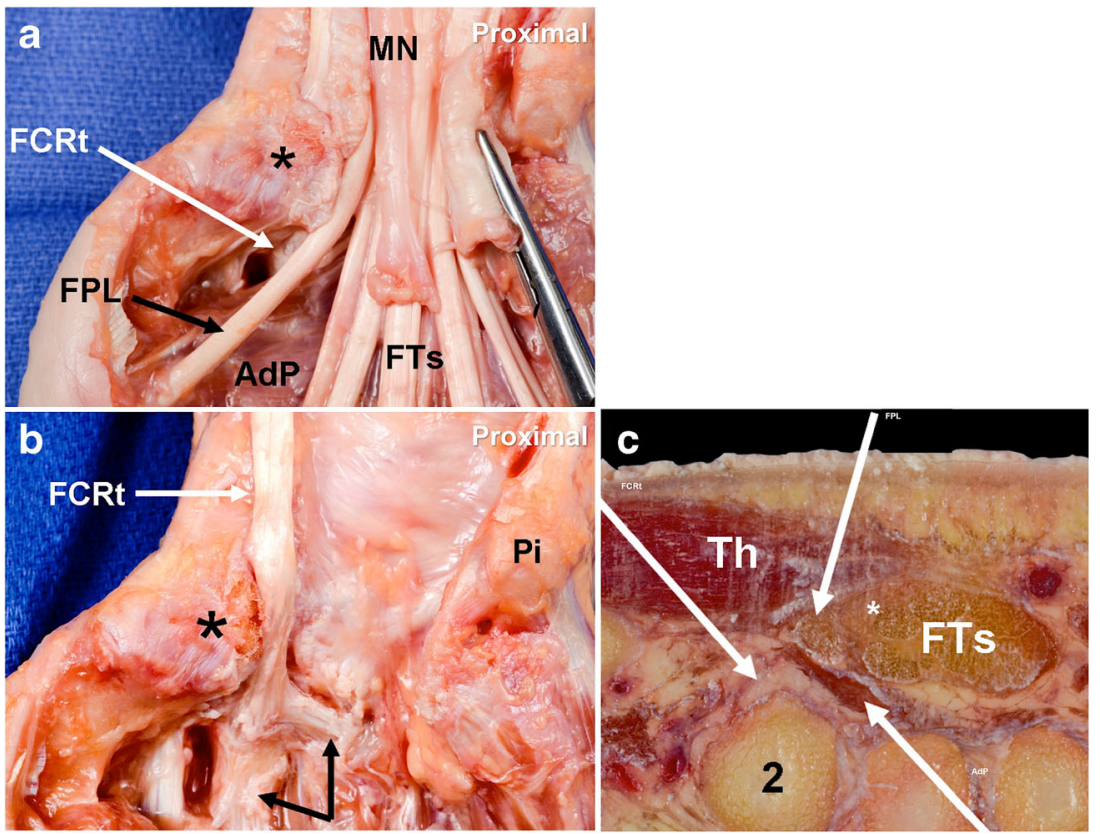

Fig. 4 Anatomy of the flexor carpi radialis tendon (FCRt) in the hand. ab Anatomic dissections demonstrating the passage of the FCRt in the hand. a The flexor retinaculum has been incised at its radial aspect and reflected ulnarly (forceps), exposing the carpal tunnel contents, including the median nerve (MN, transected distally), and flexor tendons (FTs). In this image, the FCRt insertion is obscured by the overlying FPL and the proximal aspect of the adductor pollicis muscle (AdP). b The vertical retinacular septum has been resected and a portion of the trapezium tubercle (asterisk) removed to reveal the underlying FCRt at the distal aspect of its fibro-osseous canal. Distal to the canal, the FCRt inserts primarily into the base of the second metacarpal, with a smaller, ulnarly directed slip attaching to the base of the third metacarpal (black arrows). $P i$ pisiform. c Anatomic cross-sectional image demonstrating the distal insertion of FCRt into the palmar aspect of the base of the second metacarpal (2). In this specimen, the FCRt insertion is V-shaped and covers the entire palmar aspect of the second metacarpal. A portion of the adductor pollicis muscle (AdP) is seen directly superficial to the ulnar side of the FCRt's insertion. The flexor pollicis longus tendon (FPL) lies superficial to the FCRt insertion prior to coursing radially into the thumb. Th thenar musculature, FTs flexor tendons. Asterisk median nerve. Left radial, Right ulnar

tubercle. At its exit of the tunnel, the tendon courses deeper and resumes a more flattened shape prior to inserting onto the base of 2nd and to a lesser extent 3rd metacarpal (Fig. 4). Anatomic variations of the FCR muscle and FCRt are rare [11].
Fig. 5 Technique of US examination. a-b Positions of the transducer in obtaining long (a) and short (b) axis sonograms over the proximal FCRt. $\mathbf{c}-\mathbf{d}$ Positions of the transducer in obtaining long (c) and short (d) axis sonograms over the distal FCRt. In $\mathbf{c}$ and $\mathbf{d}$, note adjustments of the transducer to set the distal tendon perpendicular to the US beams and to facilitate its assessment
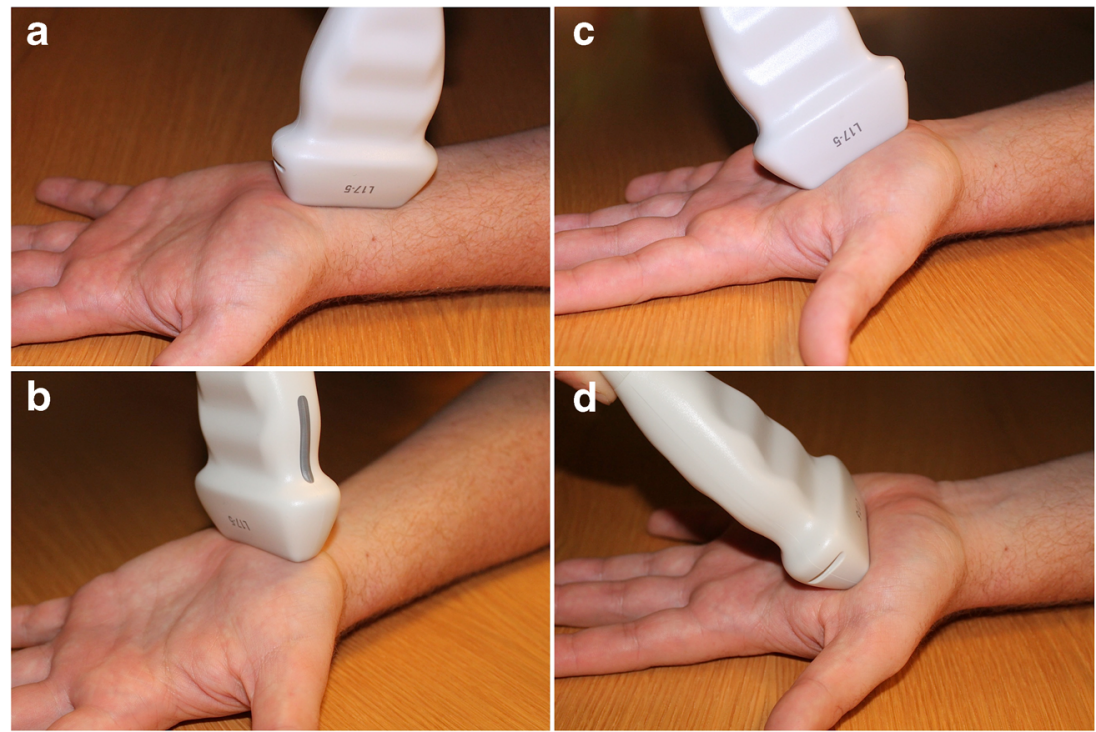

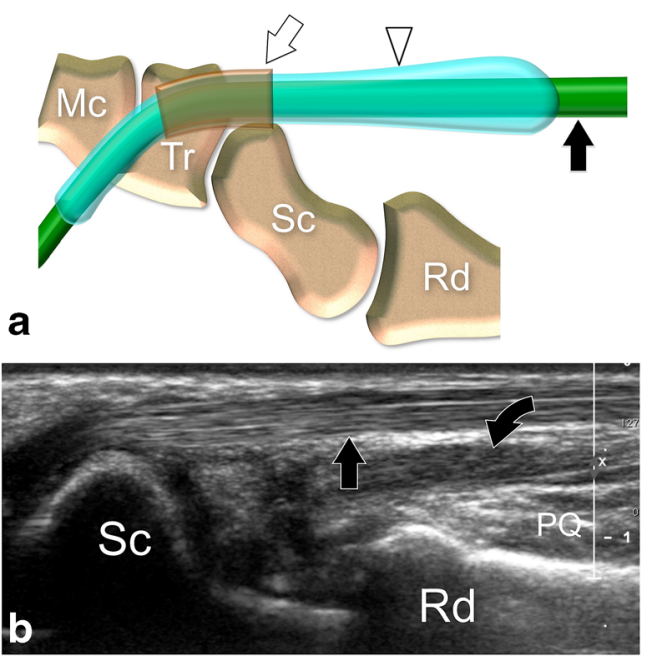

Fig. 6 Normal US anatomy. Sagittal plane. Transducer position as in Fig. 5a. a Sagittal schematic drawing showing the FCRt (black arrow) anteriorly to the radius (Rd), scaphoid (Sc) and trapezium (Tr). At the wrist level, a synovial sheath (white arrowhead) surrounds the tendon as it runs under its retinaculum (white arrow). The tendon then reflects on the palmar aspect of the scapho-trapezio-trapezoid joint to deepen abruptly prior to its insertion. $M c$ first metacarpal. b Corresponding sonogram. The normal tendon (black arrow) has a hyperechoic, regular fibrillar pattern and sharp borders. Note the close relationship of the tendon and the palmar aspect of the distal pole of the scaphoid. The thin synovial sheath is not detectable in normal conditions. Curved arrow flexor pollicis longus tendon; $P Q$ pronator quadratus muscle
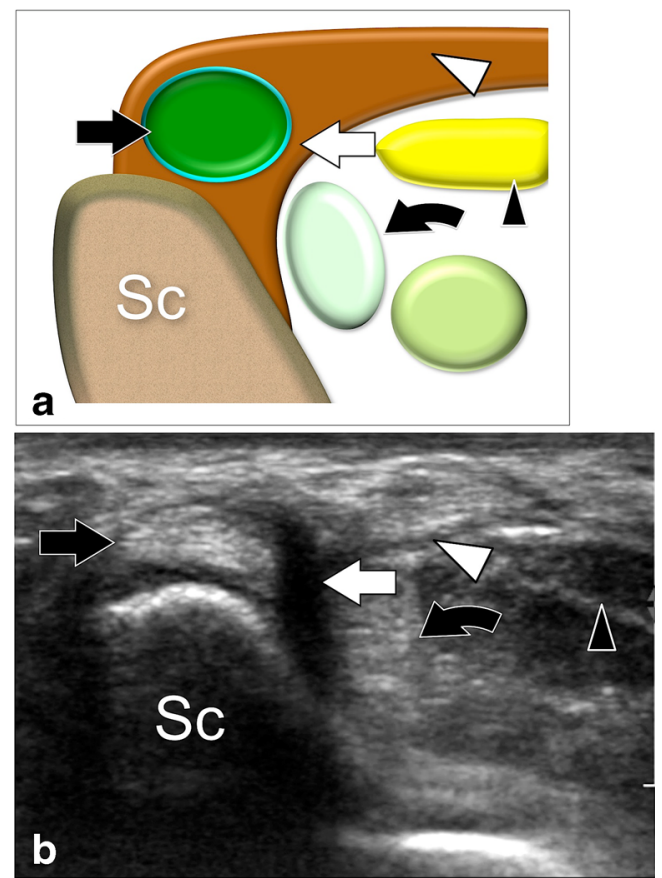

Fig. 7 Normal US anatomy. Axial plane. Transducer position as in Fig. 5b. a Schematic drawing and $\mathbf{b}$ corresponding axial sonogram obtained at the distal pole of the scaphoid $(\mathrm{Sc})$. Note the close relationship of the FCRt (black arrows) with the scaphoid. The tendon is surrounded by its retinaculum. Note the vertical retinacular septum (white arrow), which is in continuity with the flexor retinaculum (white arrowhead). Inside the carpal tunnel, note the flexor pollicis longus tendon (black curved arrow) and, more superficially, the median nerve (black arrowhead)

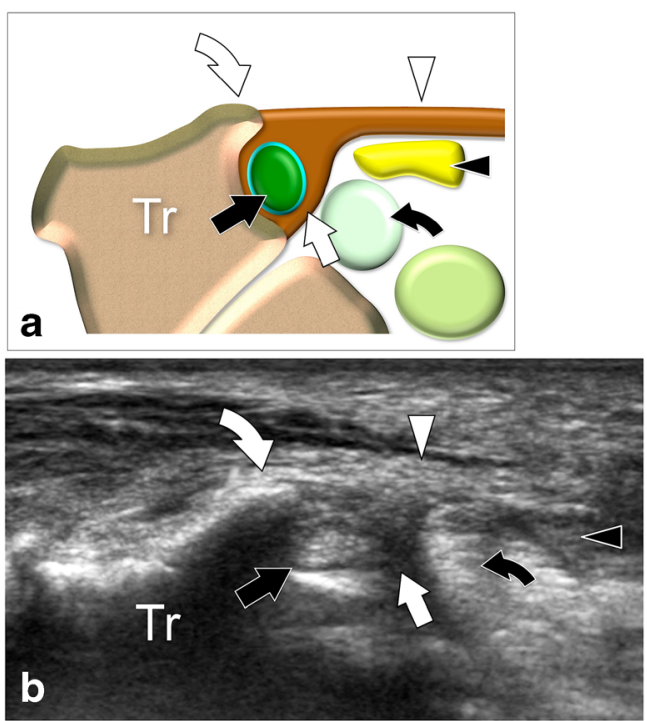

Fig. 8 Normal US anatomy. Axial plane. Transducer position slight distal then in Fig. 5b. a Schematic drawing and $\mathbf{b}$ corresponding axial sonogram obtained at the trapezium level (Tr). The FCRt (black arrows) is displayed in its osteo-fibrous canal. It is surrounded radially by the trapezium body, anteriorly by the tubercle of the trapezium (white curved arrows) and the flexor retinaculum (white arrowheads), ulnarly by the vertical retinacular septum (white arrows). Dorsally, the vertical retinacular septum inserts into the body of the trapezium and constitutes the dorso-ulnar wall of the osteo-fibrous canal. Black curved arrows flexor pollicis longus tendon; black arrowheads median nerve

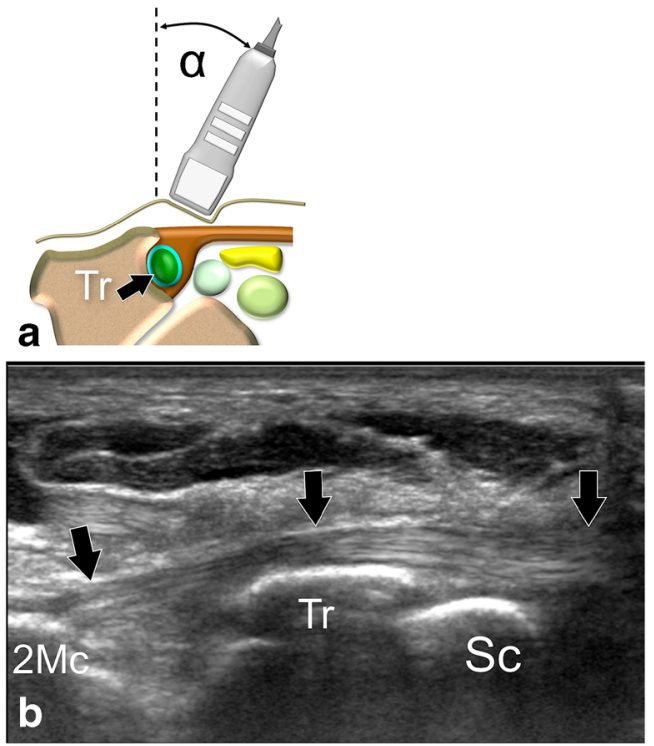

Fig. 9 Normal US anatomy. Sagittal plane. Transducer position as in Fig. 5 c. a Schematic drawing and $\mathbf{b}$ oblique sagittal sonogram obtained at the distal part of the FCRt (black arrows) with the wrist flexed at $30^{\circ}$. The transducer is inclined ulnarly ( $\alpha$ in a) to allow the ultrasonic beams to avoid the trapezium (Tr) tubercle. The image shows the FCRt, from proximal to distal (right to left), over the scaphoid (Sc), in its osteofibrous canal in close relationship with the trapezium (Tr) and to its insertion into the second metacarpal $(2 \mathrm{Mc})$. Wrist flexion enables the FCRt to be perpendicular to the US beams. This adjustment allows a more precise analysis of the tendon's fibrillary structure by minimizing the anisotropy phenomenon. Also note the excellent visualization of the tendon's insertion on the second metacarpal by using this technique 


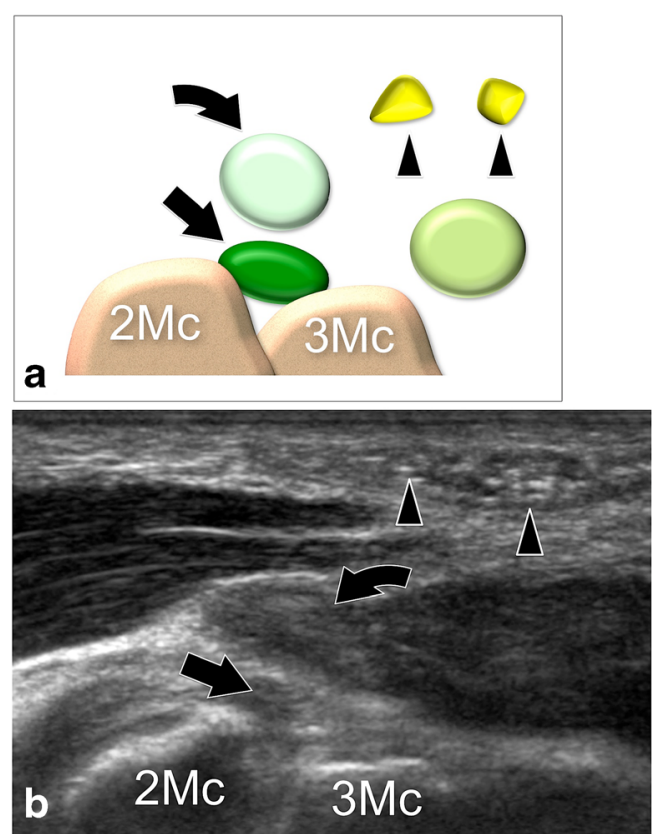

Fig. 10 Normal US anatomy. Axial plane. Transducer position as in Fig. $5 \mathrm{~d}$. a Schematic drawing and $\mathbf{b}$ corresponding axial sonogram made at the pre-insertional part of the FCRt (black arrow) near the base of the second $(2 \mathrm{Mc})$ and third $(3 \mathrm{Mc})$ metacarpals. As the tendon deviates deep in this area, its visualization can be improved by tilting dorsally the transducer or by examining the wrist flexed at approximately $30^{\circ}$. The FPL tendon (curved arrow) is, at this level, superficial to the FCRt. Arrowhead distal branches of the median nerve
The proximal third of the FCRm is vascularized by the brachial artery, whereas the distal two-thirds is vascularized by the radial artery [11]. The FCR is innervated primarily by the median nerve, however, in more than half of the cases according to a microdissection study, both the median nerve and a branch of the anterior interosseous nerve combine to innervate the FCR [12].

The FCRm participates in wrist flexion and, to a lesser extent, its radial deviation [13]. It also contributes to the stability of the scapholunate joint. While contracting, the FCR contributes to the supination of the scaphoid and pronation of the trapezium, coapting the scapholunate joint and reducing tension on the dorsal scapholunate ligament [14].

\section{US examination technique and normal US anatomy}

Conventional radiographs should be obtained prior to US as they provide an overview of the osseous and articular structures of the wrist.

\section{US examination technique}

Since the FCRt is a superficial structure, a multi-frequency linear probe with high resolution $(17-5 \mathrm{MHz})$ is
Fig. 11 Flexor carpi radialis brevis (FCRB) muscle and tendon. a-d Axial US images, obtained from proximal (a) to distal (d), show the FCRB muscle (large white arrow) and tendon (small white arrow). This accessory muscle is located deep to the radial artery (white arrowhead) and the FCRt (black arrow), radial to the in flexor pollicis longus tendon (curved arrow) and palmar to the distal end of the radius. In $\mathbf{d}$, the FCRB tendon is seen inserting into the vertical retinacular septum of the FCRt (black arrow). e Sagittal US image showing the relationship between the FCR tendon and the FCRB muscle and tendon. $S c$ scaphoid
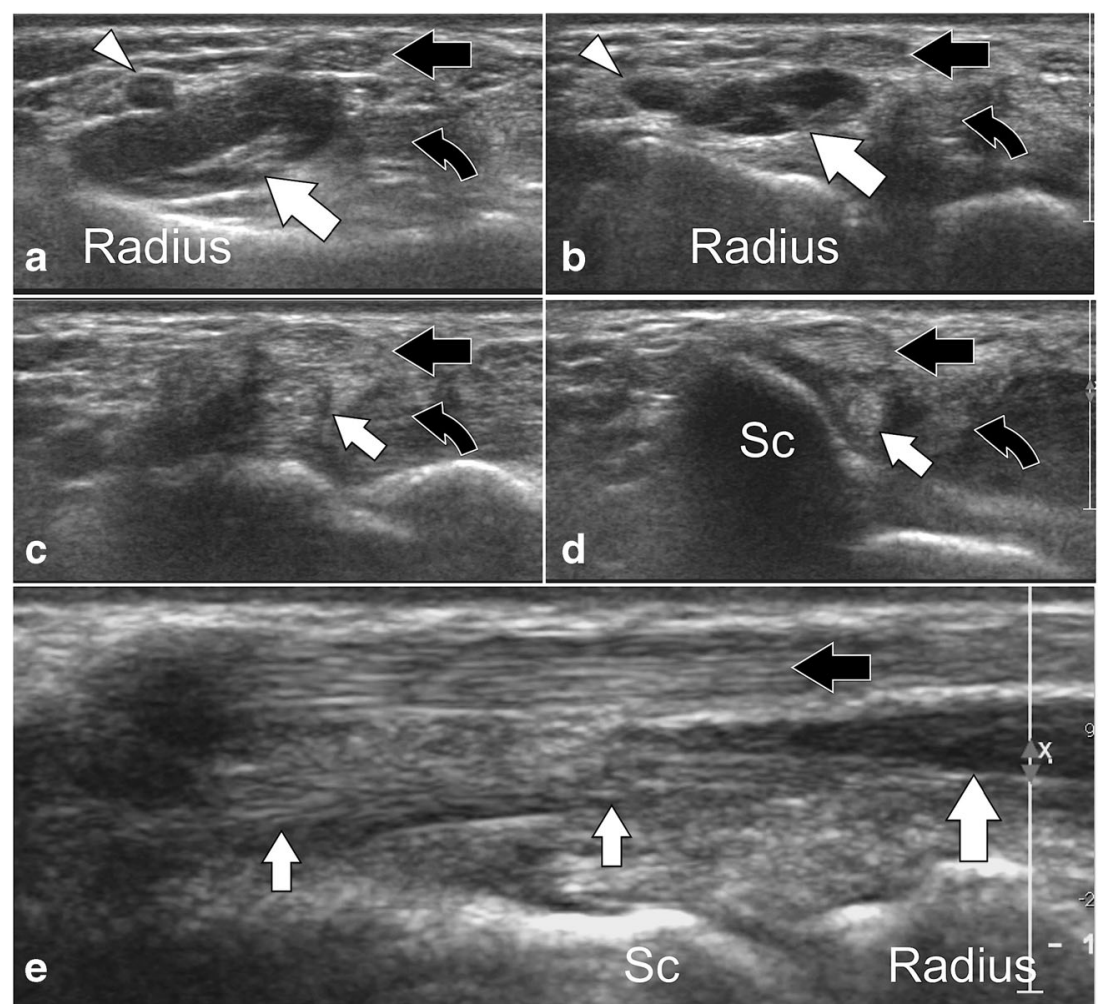
Fig. 12 Anatomic variation of the FCR distal insertion. $\mathbf{a}-\mathbf{f}$ Axial sonograms (a, c, e) with corresponding MRI images (b, d, f) obtained at the level of the pronator quadratus muscle (PQ) (a, b), distal end of the radius (c, d) and the scaphoid (Sc) (e, f). The FCRt (large black arrows) is located more ulnarly then usually, between the palmaris longus tendon (small black arrows) and the median nerve (black arrowheads). Images obtained at the level of the scaphoid $(\mathbf{e}, \mathbf{f})$ depict its insertion into to the proximal edge of the flexor tendons retinaculum. Note absence of the FCRt (open arrows) in its normal location, palmar to the distal scaphoid. White arrowhead radial artery; curved black arrows flexor pollicis longus tendon; FTs flexors tendons
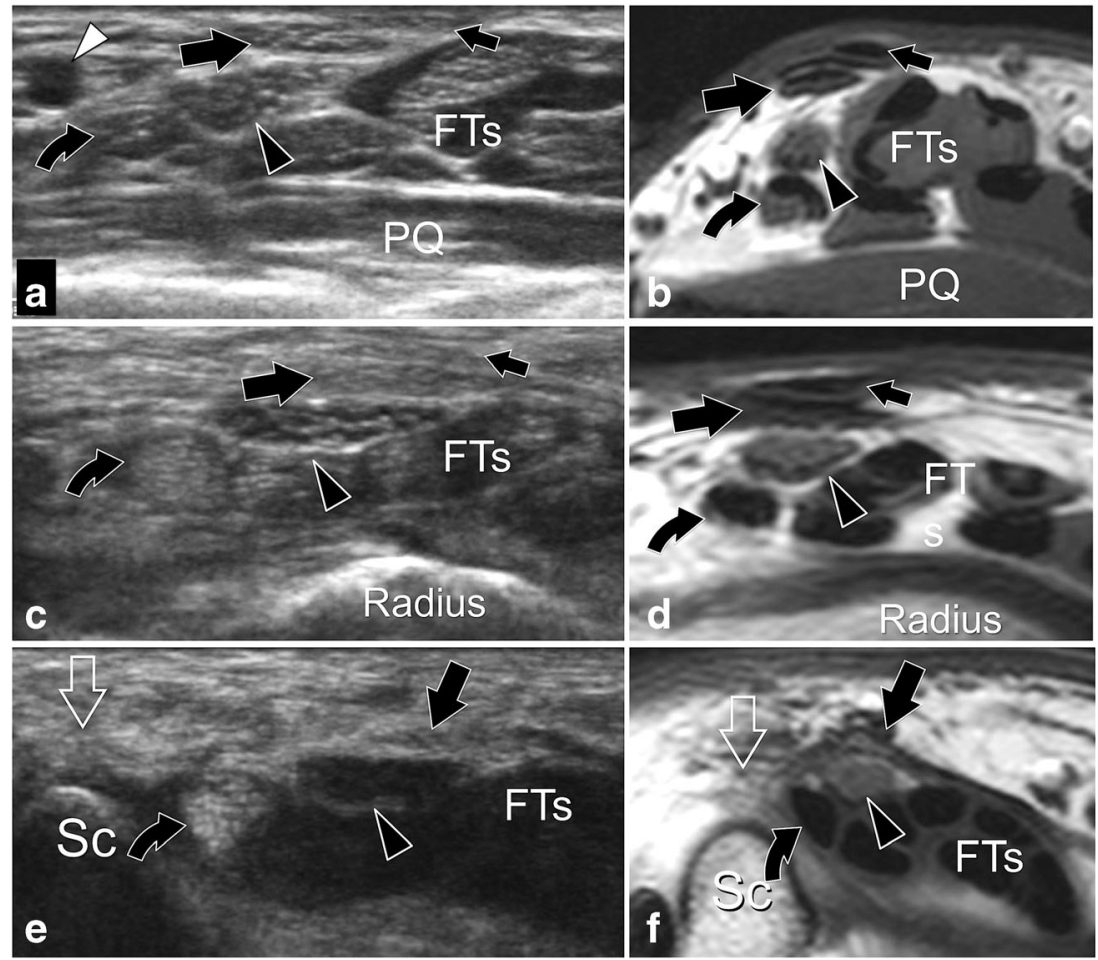
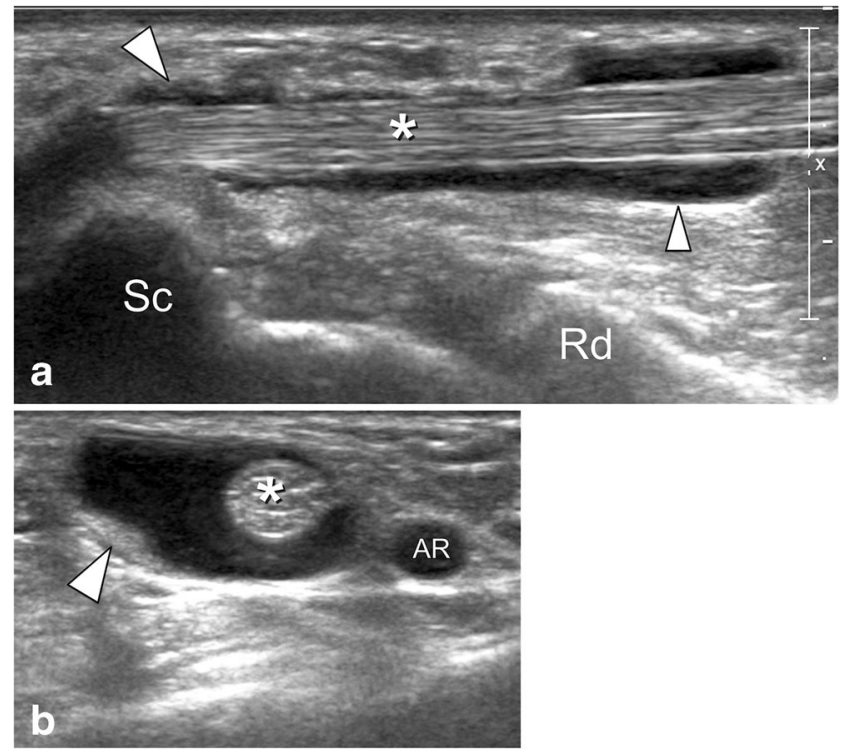

Fig. 13 Isolated tenosynovitis. a Sagittal and $\mathbf{b}$ axial US images show a normal hyperechoic fibrillar pattern of the FCRt $(*)$, which appears surrounded by an anechoic synovial effusion (small arrowhead). Note localized hypertrophy of the synovial tendon sheath (large arrowhead). The appearance is typical of tenosynovitis without any evidence of associated tendinopathy. The FCRt travels ulnar to the radial artery (RA) and anteriorly to the radius (Rd) and the scaphoid (Sc)
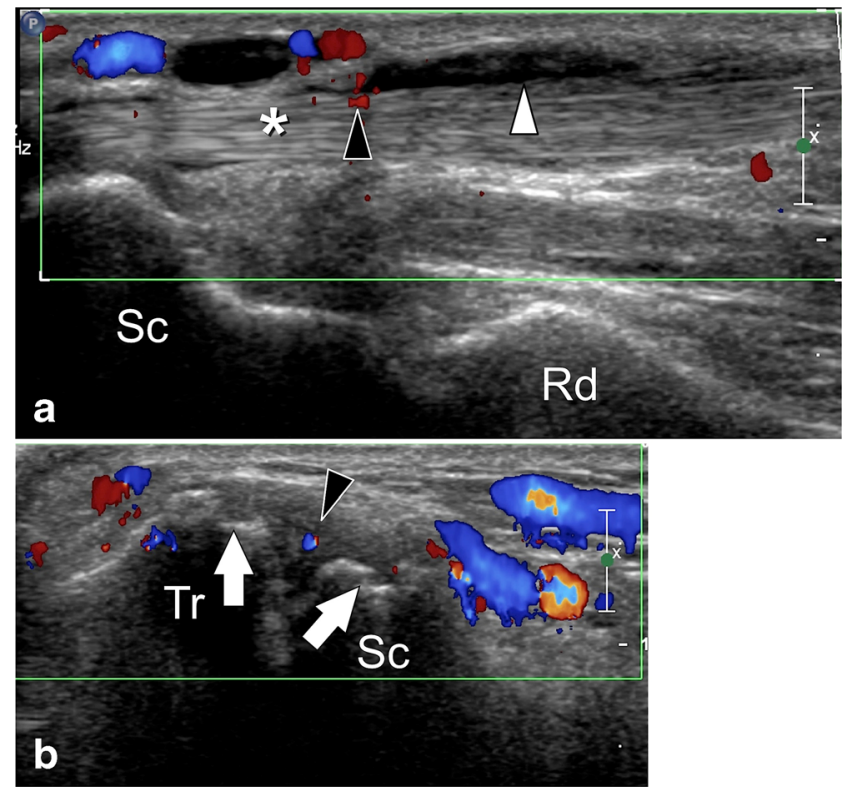

Fig. 14 Isolated tenosynovitis secondary to osteoarthritis of the scaphoid-trapezium-trapezoid joint complex (STT). a Sagittal color Doppler image shows the normal appearing tendon $(*)$ surrounded by an anechoic synovial effusion (white arrowhead). Note hyperemia of the synovial sheath (black arrowhead), reflecting local inflammation. b Sagittal oblique color Doppler of the STT shows thickening and hyperemia (black arrowhead) of the synovial membrane associated with irregularities of the articular surfaces (white arrows). US findings are highly suggestive of STT osteoarthritis associated with active joint synovitis and FCR tenosynovitis due to local impingement. $R d$ radius; $S c$ scaphoid; $T r$ trapezium 

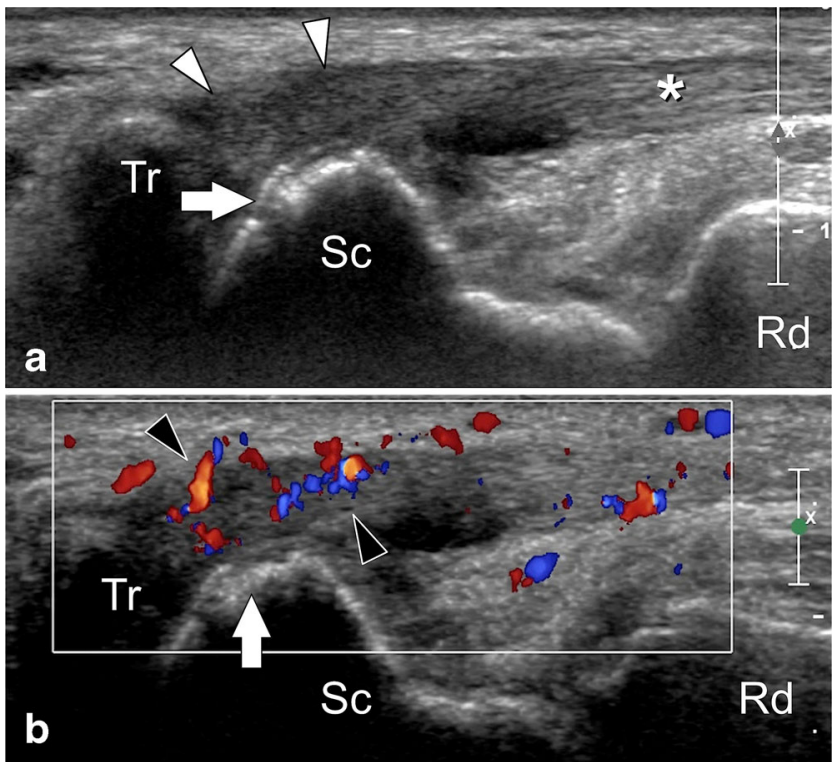

Fig. 15 Tendinopathy secondary to osteoarthritis of the scaphoid-trapezium-trapezoid complex (STT). a Sagittal and b sagittal color Doppler US images showing a swollen, irregular and hypoechoic appearance of the FCRt (white arrowheads) at the level and proximal to the STT consistent with tendinopathy. Note the local loss of the fibrillar appearance and hyperemia (black arrowheads) at color Doppler reflecting intratendinous neovascularization. The proximal tendon $(*)$ shows a normal appearance. The STT shows irregularities of the articular surfaces (white arrows) consistent with osteoarthritis. $R d$ radius; Sc scaphoid; $T r$ trapezium recommended for evaluation. Liberal use of US gel will optimize transducer contact despite wrist surface irregularities. The use of a compact linear transducer may assist with visualization of the distal tendon as it courses through its osteofibrous tunnel towards its metacarpal insertion.

The US examination is performed with the patient sitting in front of the examiner with the forearm supinated and resting on the examination table. The FCR is systematically scanned from proximal to distal, evaluating the FCRm, musculo-tendinous junction, FCRt and FCRt insertion on long and short axis views (Fig. 5). Specific attention is directed to the wrist region where the majority of the FCRt pathologies occur. As the FCRt passes under the trapezium tubercle, its pre-insertional portion changes direction, necessitating transducer adjustments to provide better visualization (see details below). Dynamic US examination with wrist flexion and extension can facilitate identification of partial tears or regions of impingement. Whenever there is difficult interpretation, comparison with the contralateral side is mandatory. The sonographic examination is always completed by exploration of neighboring structures as dictated by the clinical scenario.

Color Doppler is routinely obtained to detect the presence of hypervascular changes within the FCRt, its synovial sheath, or adjacent structures. Due to the superficial position of these structures, transducer pressure must be minimized to avoid squeezing the vessels and producing false-negative examination.
Fig. 16 Rheumatoid tenosynovitis associated with joint damages. a Sagittal color Doppler sonogram of the posterior aspect of the wrist shows radiocarpal and midcarpal synovial membrane hypertrophy associated with hyperemia (black arrows) reflecting an active inflammatory process. $\mathbf{b}-\mathbf{c}$ Sagittal (b) and axial (c) color Doppler US images showing an active inflammatory pannus (black arrowheads) surrounding the normal FCRt $(*)$. d-e, sagittal (d) and axial (e) T1-weighted post-gadolinium MRI images show evident enhancement of the FCR synovial sheath (black arrowheads) and of the synovial membrane (black arrows) of the wrist joints confirming the sonographic findings. $C p$ capitate; Lun lunate; $R d$ radius; $S c$ scaphoid; $\operatorname{Tr}$ trapezium
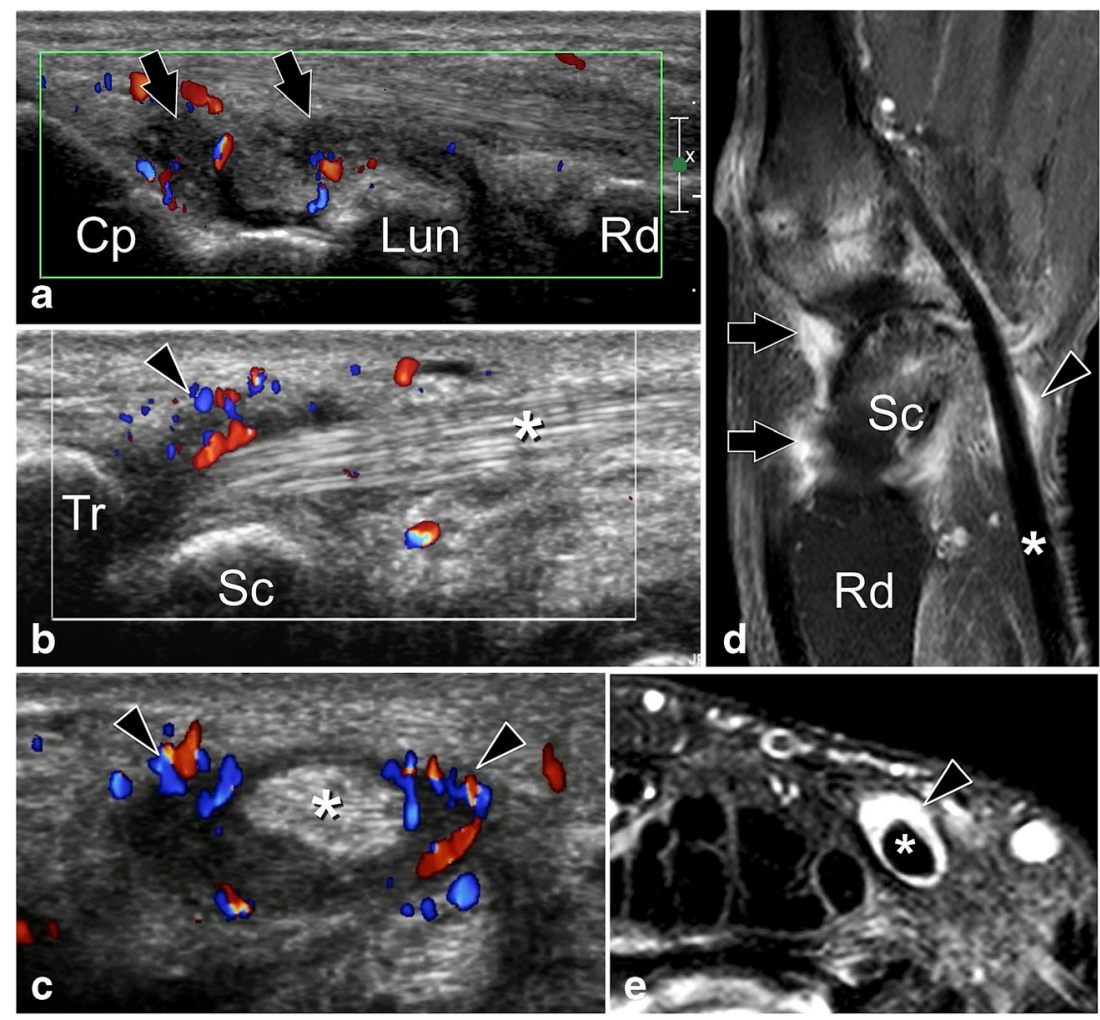


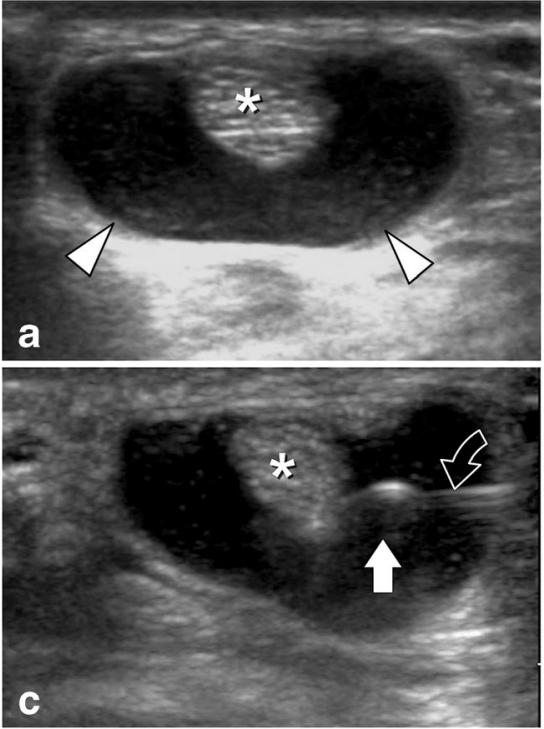

Fig. 17 Isolated tenosynovitis. US-guided infiltration. a-d Axial US images obtained over the proximal tendon. a US shows the tendon $\left({ }^{*}\right)$ surrounded by an anechoic effusion distending the synovial sheath (white arrowheads). b A 25-gauge needle (curved black arrow) is inserted into the synovial sheath by radial approach, under real-time US guidance. This

\section{Normal sonographic anatomy}

On long-axis views, the FCRm appears as a pennate structure consisting of hyperechoic linear bands (perimysium) located within a hypoechoic background (muscle fibers). On shortaxis views, the muscle is hypoechoic with a "starry night" appearance [15]. The FCR's bipennate structure is more evident at the myo-tendinous junction, where US visualizes

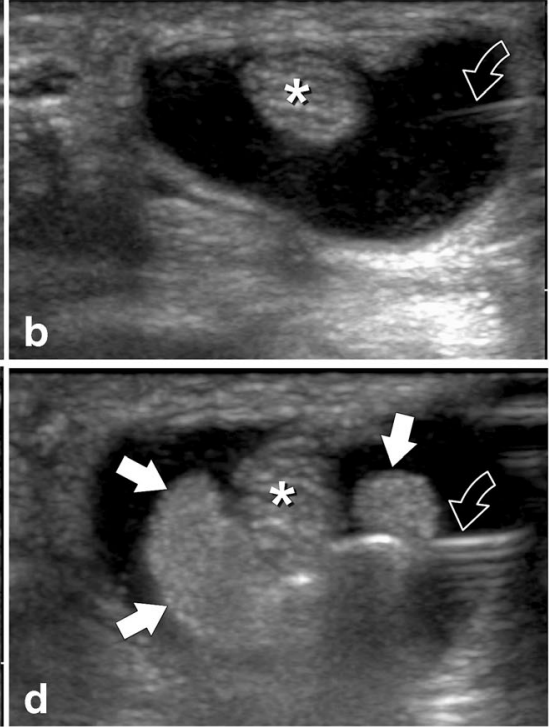

image confirms the correct position of the needle tip. c-d Real-time visualization of the progression of the injection (local anesthetics and corticosteroids mixture). Sonograms show the hyperechoic solution (white arrows) gradually filling the synovial space

the fibroadipose septa (hyperechoic) joining the central aponeurosis (hyperechoic). Mechanical myo-aponeurotic lesions, though extremely rare, can appear in this region [16].

At the wrist, the FCRt appears hyperechoic and exhibits a typical internal fibrillar echotexture on both short- and long-axis images. The thin, hypoechoic synovial sheath is not seen in normal states (Fig. 6). The FCRt is well

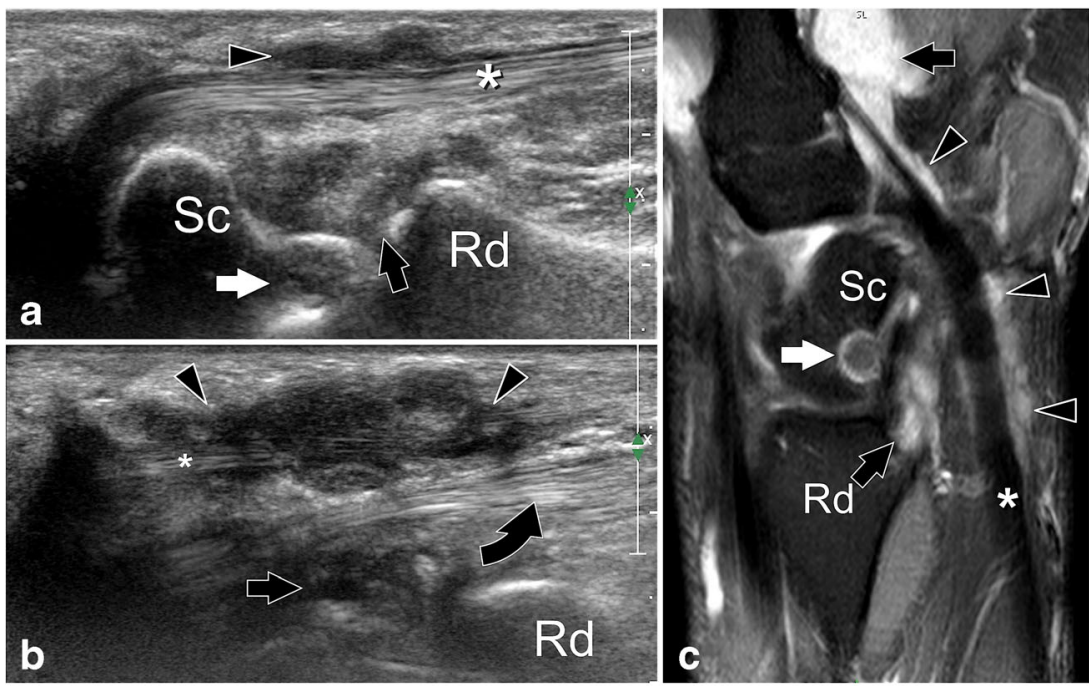

Fig. 18 Pigmented villonodular tenosynovitis associated with joint damages. a-b Sagittal US images obtained on the palmar aspect of the wrist show marked thickening of the FCRt $\left(^{*}\right)$ synovial sheath (black arrowheads). In a, note the large erosion (white arrow) of the palmar face of the scaphoid (Sc) due to hypertrophy of the synovial membrane (black arrows) of the radio-carpal joint. Curved arrow flexor pollicis longus tendon. c Sagittal T1-weighted post-gadolinium MR image corresponding to the sagittal US on a, shows hypertrophy and enhancement of the synovial sheath (black arrowheads) of the FCRt (*) and of the synovial membrane (black arrows) of the radio-carpal and midcarpal joints. Note the erosion (white arrow) of the proximal scaphoid (Sc) 

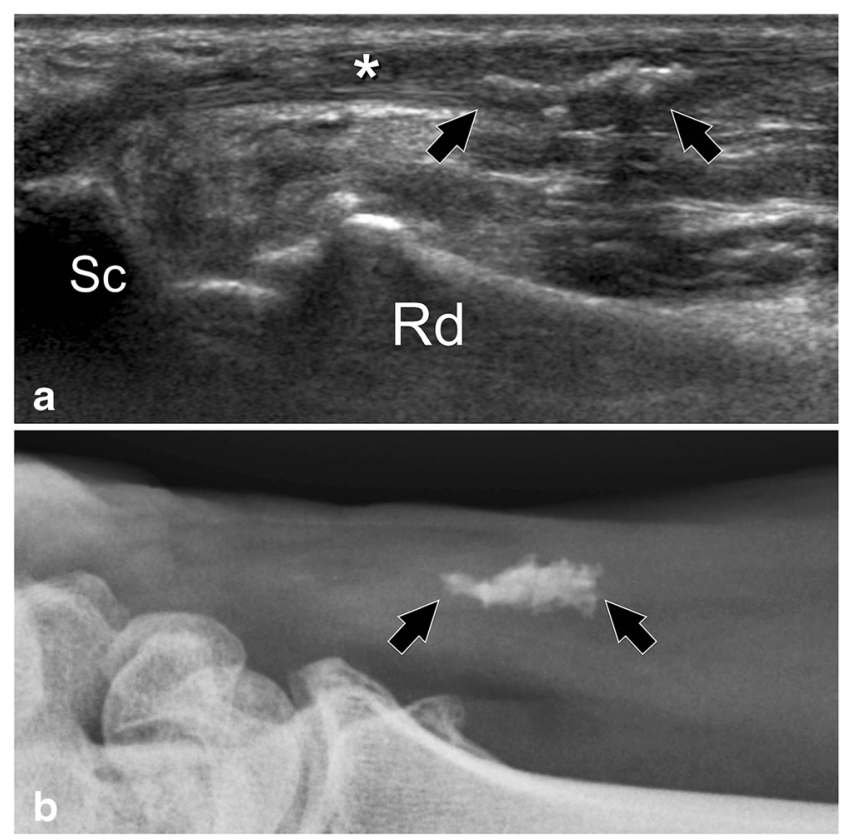

Fig. 19 Intratendinous calcification. a Sagittal US image obtained over the proximal FCRt $\left({ }^{*}\right)$ shows a hyperechoic lesion (black arrows) located in the tendon and presenting mild posterior acoustic shadowing. The appearance is typical of a tendon calcification. b Corresponding standard radiography confirms the sonographic findings

visualized superficial (palmar) to the scaphoid. At this level, the vertical retinacular septum is more evident on transversal axis and may appear either hyperechoic or hypoechoic depending on the degree of anisotropy (Figs. 7 and 8). Inside the FCRt osteofibrous tunnel, the acoustic shadowing from the superficially located trapezium tubercle partially prevents the FCRt US visualization, a situation that is often exaggerated in the presence of STT arthritis. This problem can be at least partially ameliorated by oblique longitudinal imaging obtained by tilting the transducer ulnarly. This technique allows the US beam to reach the tendon by avoiding the bony surface of the trapezium tubercle (Fig. 9). Imaging the FCRt distal to the trapezium may be even more challenging as the tendon changes direction and therefore appears obscured and hypoechoic due to anisotropy (Fig. 10). In this region, the FCRt visualization can be improved by dorsally inclining the probe or by bending the wrist at approximately $30^{\circ}$. These two adjustments set the tendon perpendicular to the US beam and can facilitate its assessment to its metacarpal insertion (Fig. 9).

The flexor carpi radialis brevis (FCRB) is an uncommon accessory muscle found on the volar aspect of the forearm (Fig. 11). It typically arises as a small muscle from the anterior aspect of the radius and inserts either within the FCR osteofibrous tunnel adjacent to the FCR tendon and onto the retinacular septum, or onto the trapezium after passing through the FCR osteofibrous tunnel [17]. Variation of the FCRt insertion are rare (Fig. 12).

US may also be utilized to evaluate several neighboring structures, including but not limited to: (1) Ulnarly-the palmaris longus, flexor digitorum superficialis and flexor digitorum profundus tendons, as well as the median nerve
Fig. 20 Traumatic tendinopathy caused by a conflict with a scaphoid fracture. a-b Axial (a) and sagittal color Doppler (b) US images showing slight irregularities of the FCRt $(*)$ secondary to a conflict with a mildly displaced fracture (black arrow) of the scaphoid (Sc). In a, note the partial thickness tear of the deep face of the tendon located in contact with the fracture. In $\mathbf{b}$, hyperemia of the tendon sheath (white arrow) reflects a local inflammatory process. c Axial CT-scan obtained after US confirmed the scaphoid (Sc) fracture. Note the excellent correlation between the fracture appearance in $\mathbf{a}$ and $\mathbf{c}$
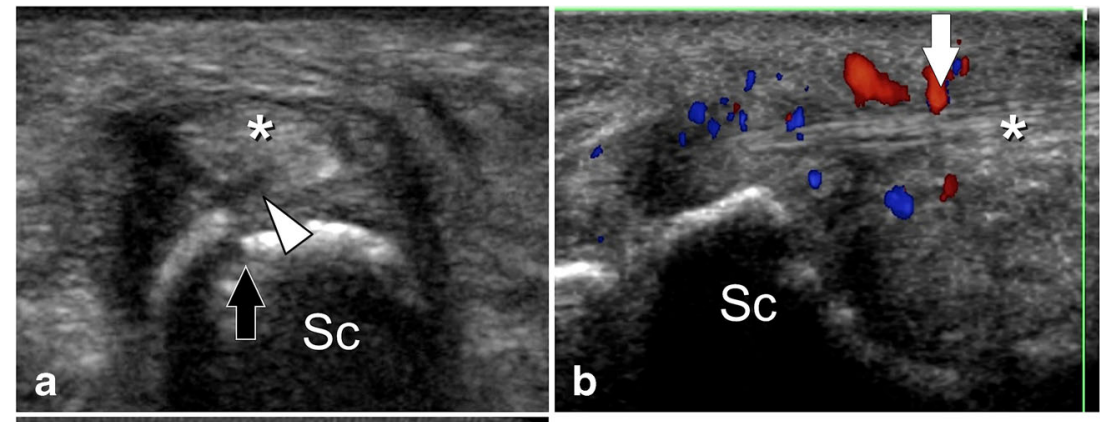

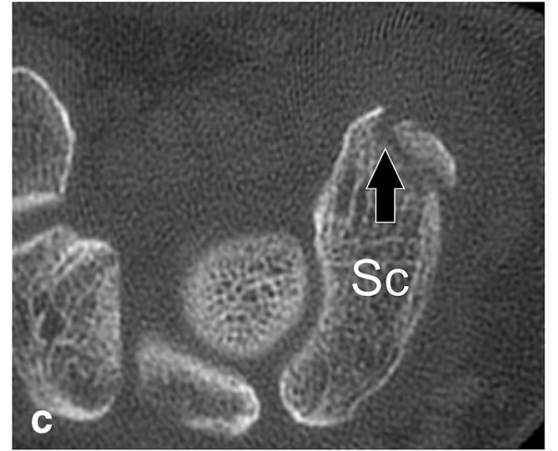




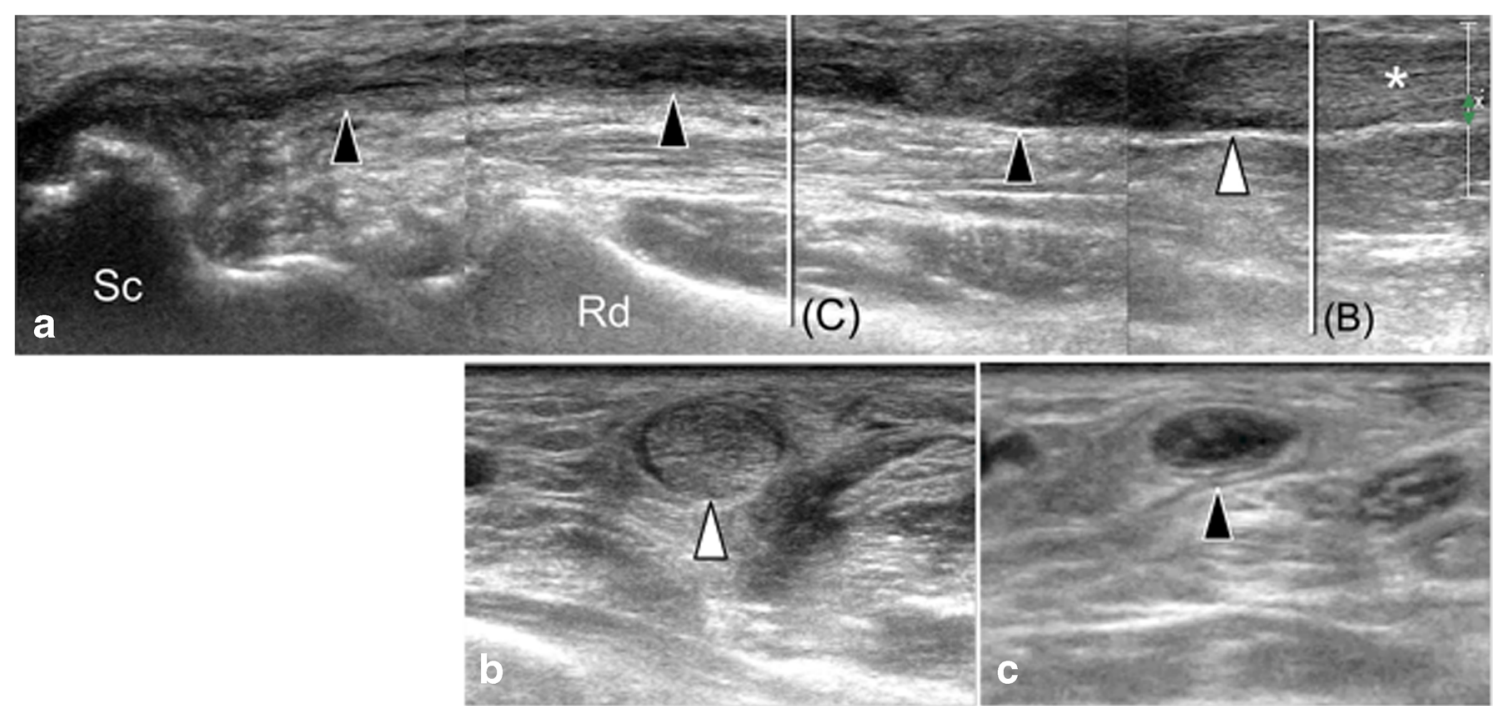

Fig. 21 Complete tendon tear in previous tendinopathy. a Multi-images reconstructed sagittal sonogram showing a complete FCRt $\left(^{*}\right)$ tear with substantial retraction of the proximal stump which shows a thickened and irregular appearance (white arrowhead). The empty synovial sheath (black arrowheads) has a thickened hypoechoic wall and contains a small amount of fluid. b, c Axial US images (obtained at level indicated in a) showing the proximal stump (white arrowhead) and the distal empty synovial sheath (black arrowhead). Sc scaphoid; $R d$ radius and its palmar cutaneous branch, and (2) Radially - the FPL tendon, radial artery, brachioradialis tendon, superficial radial nerve, and the wrist first extensor compartment [18].

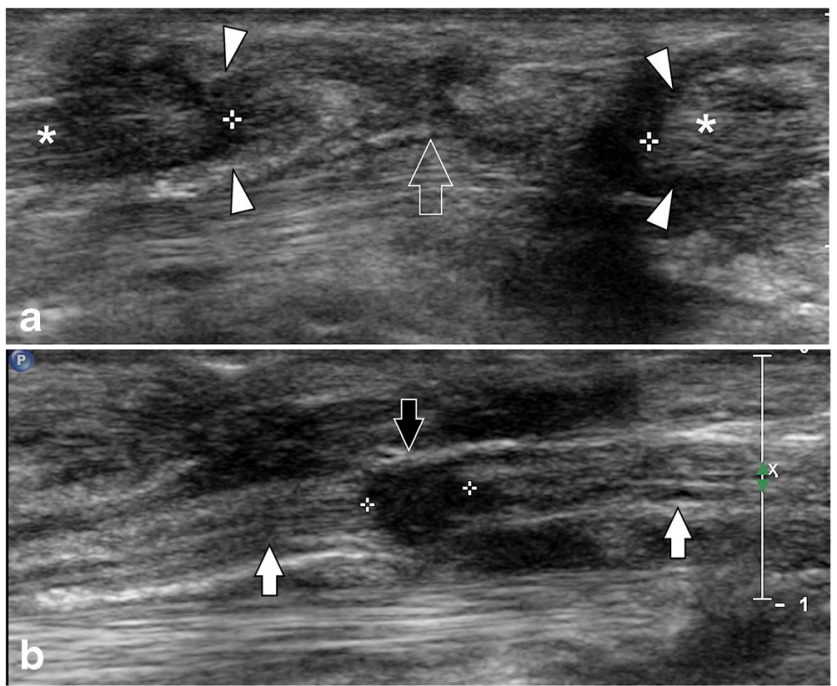

Fig. 22 Complete tendon tear. Associated section of the median nerve. a Sagittal US image obtained on the palmar aspect of the wrist showing a complete FCRt $(*)$ tear due to a stab wound. The ends of the tendon (white arrowheads) are separated by a hypoechoic area (open arrow, callipers). b Sagittal US image obtained ulnar to a highlighting concomitant full-thickness interruption (black arrow, callipers) of the median nerve (white arrows)

\section{Pathologic sonographic appearance}

FCRt disorders associated with degenerative lesions of the STT complex

The FCRt impingement in the region of the STT complex can cause a large spectrum of tendinous lesions, including tenosynovitis (Figs. 13 and 14) with or without tendinopathy, isolated tendinopathy (Fig. 15), and partial or complete tendon tears. FCRt tenosynovial sheath cysts may also occur and sometimes can communicate with the STT joint [1].

Clinically, these conditions present as volar radial wrist pain accompanied by palpatory tenderness and variable swelling. Symptoms may be increased by resisted wrist flexion or passive wrist extension.

\section{Inflammatory tendinopathy}

FCR tenosynovitis is characterized by effusion and/or thickening of the synovial membrane surrounding the FCRt. Tendinopathy is manifested as tendon thickening and heterogenous hypoechogenicity with or without superimposed tearing. When the tenosynovitis is of mechanical origin, the effusion prevails. In contradistinction, when tenosynovitis is associated with RA or other chronic inflammatory disorders, the thickening of the synovial membrane (pannus) prevails (Fig. 16) [19, 20]. Color Doppler allows evaluation of the pannus vascularity and therefore provides a measure of disease activity (Fig. 16). In chronic cases, the tenosynovial pannus may erode into the adjacent FCRt, resulting in tearing. 

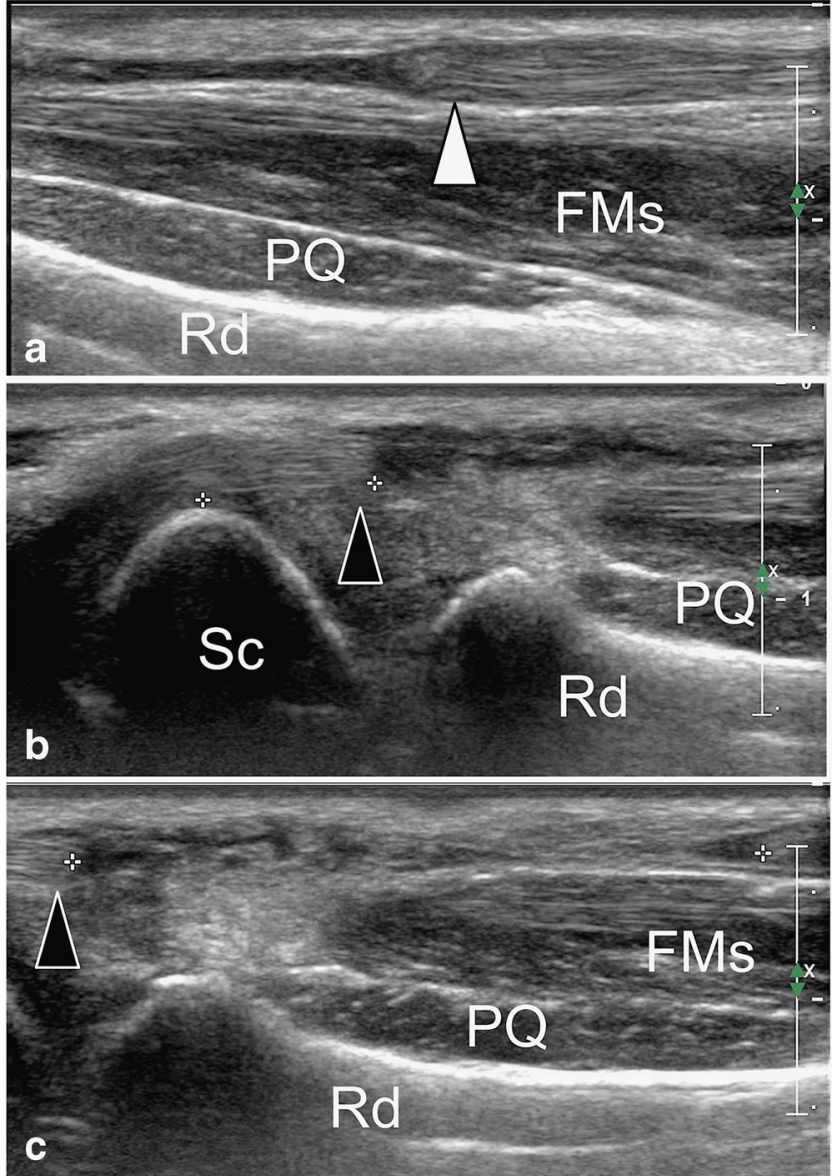

Fig. 23 Complete tendon tear. Acute tear. a-c Sagittal US images, obtained from proximal (a) to distal (c), show a complete FCRt tear secondary to a knife wound. In a, the retracted proximal stump (white arrowhead) is visualized at the level of the proximal part of the pronator quadratus muscle $(\mathrm{Pq})$. In $\mathbf{b}$, note the sharp borders of the distal stump (black arrowhead) that is located just proximal to the distal pole of the scaphoid (Sc). In c, the distance between the ends of the tendon (callipers) can be accurately measured by US and helps in choosing the proper surgical technique. $R d$ radius; FMs flexor muscles

It is thus important to always carefully evaluate the tendon's integrity to detect even small partial tears. Partial tears are diagnosed when there is partial interruption of tendon fibres whereas complete tendon ruptures appear as a gap in the tendon structure with variably retracted proximal and distal tendon stumps [21]. It is particularly important in the setting of suspected inflammatory disease to evaluate for surface erosions of the scaphoid or trapezium, as these bones lie in close proximity to the affected FCR tendon sheath. Examining the other tendons and the wrist joints then completes the examination.

US can accurately guide a needle diagnostic puncture or therapeutic infiltration of the tendon sheath (Fig. 17). In cases of infiltration, a $27-\mathrm{G}$ needle is recommended to minimize damage to surrounding structures. If a fluid aspiration is warranted, a larger bore needle (21-G) must be used. US provides real-time and precise localization of the needle in the synovial space. It also minimizes risks of puncturing adjacent structures such as tendons, nerves, or arteries. Moreover, according to several studies, sonographic-guided infiltrations are less painful and better tolerated than those guided by anatomical landmarks $[22,23]$.

Tendinopathies related to synovial membrane proliferative pathologies

The FCRt can also be affected by proliferative synovial disorders such as pigmented villonodular synovitis (PVNS). In the nodular or focal type of PVNS, US shows a well-defined heterogenous hypoechoic solid mass adjacent to the tendon. Color Doppler usually shows variable internal flow [24]. US can also determine the relationship between the mass and the neighboring structures such as tendons, vessels, nerves, and bones. In the diffuse type of PVNS, the synovium is significantly thickened, hypoechoic and is often associated with a local effusion. The US appearance of the diffuse type of PVNS (Fig. 18) is similar to that of a severe form of RA. In this latter case, the US appearance may suggest PVNS, but either MRI or biopsy is necessary for definitive diagnosis.

\section{Intratendinous calcification}

Calcification of the FCRt appears on US as a hyperechoic lesion with variable posterior acoustic shadowing (Fig. 19). Color Doppler can be use to detect local hyperemia to detect the presence of local inflammation.

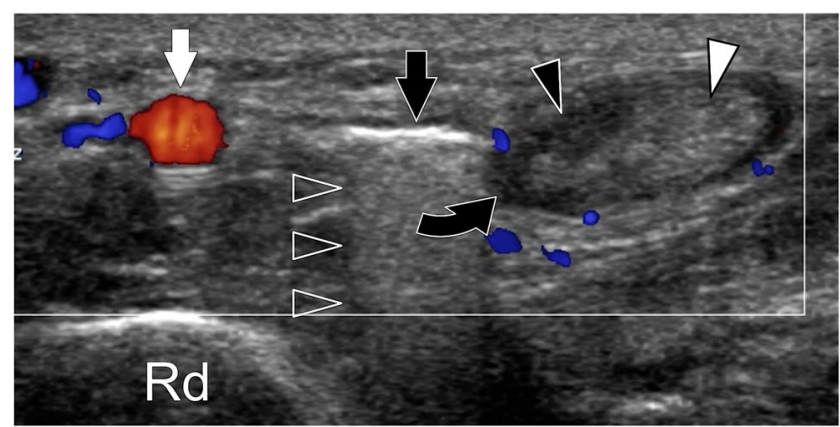

Fig. 24 Partial tendon rupture. Axial color Doppler sonogram of the palmar wrist shows a tear (black arrowhead) of the radial part of the FCRt highlighted by an irregular and hypoechoic appearance of the tendon associated with a discrete tenosynovitis (black curved arrow). The ulnar part of the tendon (white arrowhead) is normal. The tear is due to penetrating glass foreign body (black arrow) and the latter has a hyperechoic appearance and posterior reverberation artefacts (open arrowheads). The radial artery (white arrow) shows a normal internal flow signal. $R d$ radius 


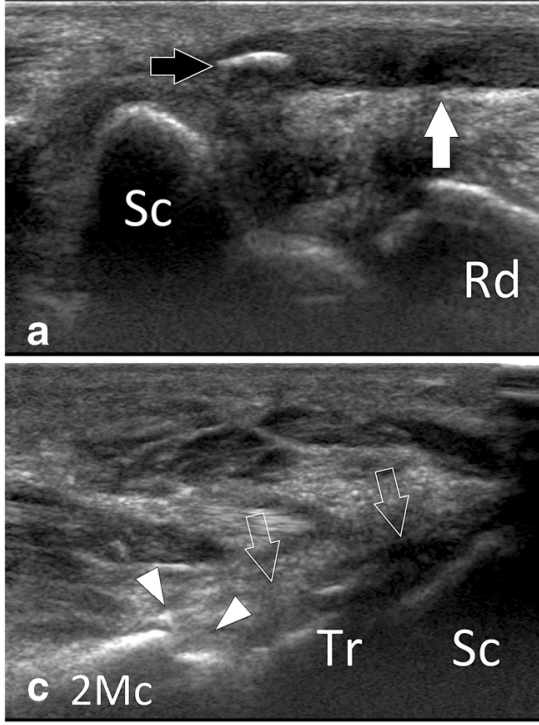

Fig. 25 Bone avulsion of the distal insertion in a patient who had a previous dorsal carpometacarpal dislocation. a-b Sagittal (a) and axial (b) US images obtained over the proximal FCRt show the swollen hypoechoic tendon (white arrow) and the avulsed bone fragment (black arrow) presenting posterior shadowing (black arrowheads). c-d Sagittal

Traumatic tendinopathy and tendon tear

Chronic trauma due to irritating bone fragments following radius [5], scaphoid (Fig. 20) or trapezium [25] fractures, or acute penetrating trauma can lead to tenosynovitis, tendinopathy and, in more severe cases, partial or complete FCRt tears. US can detect the presence of tendinopathy and determine the exact location of the conflict. In addition, US can differentiate partial versus complete tears (Fig. 20), and
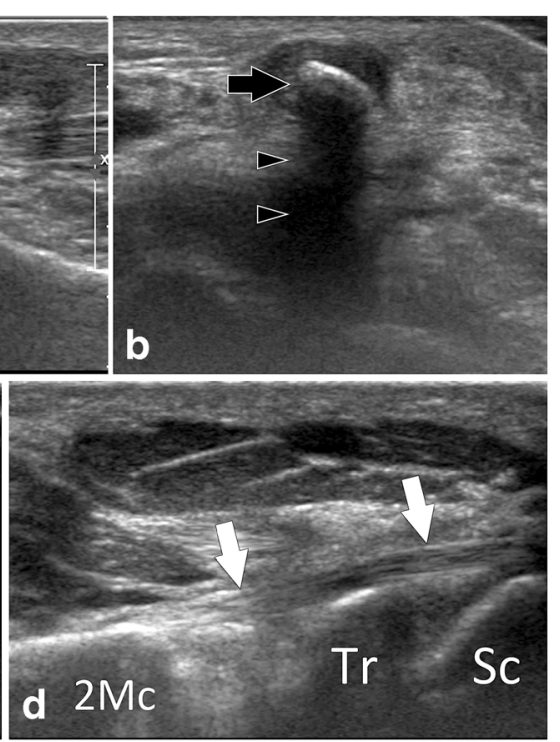

US images obtained over the affected wrist (c) and on the contralateral side (d). In c note absence of the distal FCRt (open arrows) and irregularity (white arrowheads) of the base of the second metacarpal (2Mc) due to avulsion of the FCRt. In d, note the normal FCRt inserting into the smooth cortex of the base of the second metacarpal (2Mc)
Fig. 26 Irritation by scaphoid fixation screw causing tendinopathy. a-c Axial (a), sagittal (b), and sagittal color Doppler (c) US images showing irritation of the FCRt $(*)$ by a scaphoid (Sc) fixation screw (black arrows). In a, note the threads of the screw appearing as thin, hyperechoic parallel lines. The synovial sheath (white arrowheads) is hypoechoic, thickened, and hyperemic on color Doppler (black arrowhead) indicating an active local inflammatory process. $\mathrm{Tr}$ trapezium
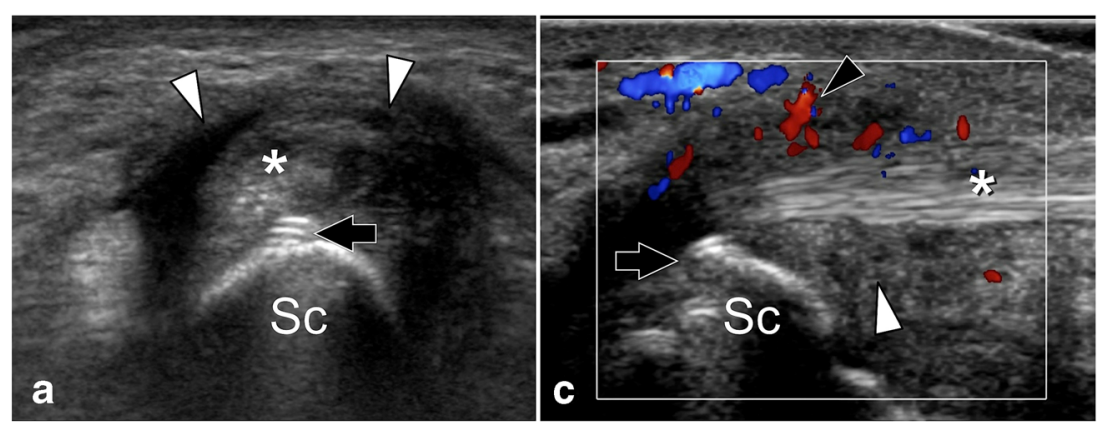

measure the gap between tendon stumps in the latter case (Fig. 21). Color Doppler can show local hyperemia if the tear is recent.

US can also accurately assess traumatic FCRt tears (Figs. 22, 23) and localize foreign bodies in proximity to the FCRt (Fig. 24). Regardless of composition, foreign bodies often appear as hyperechoic fragments with posterior artefacts such as acoustic shadowing and reverberation [26]. They can be surrounded by an abscess when acute or associated with a

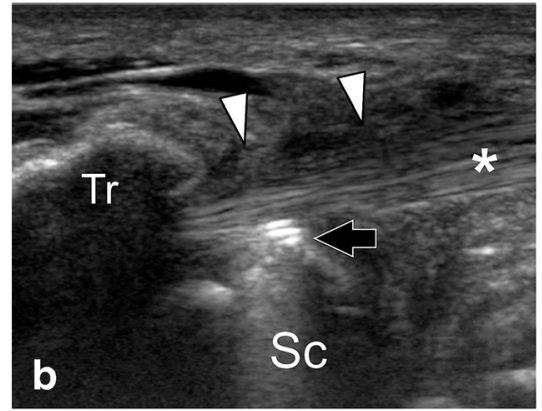



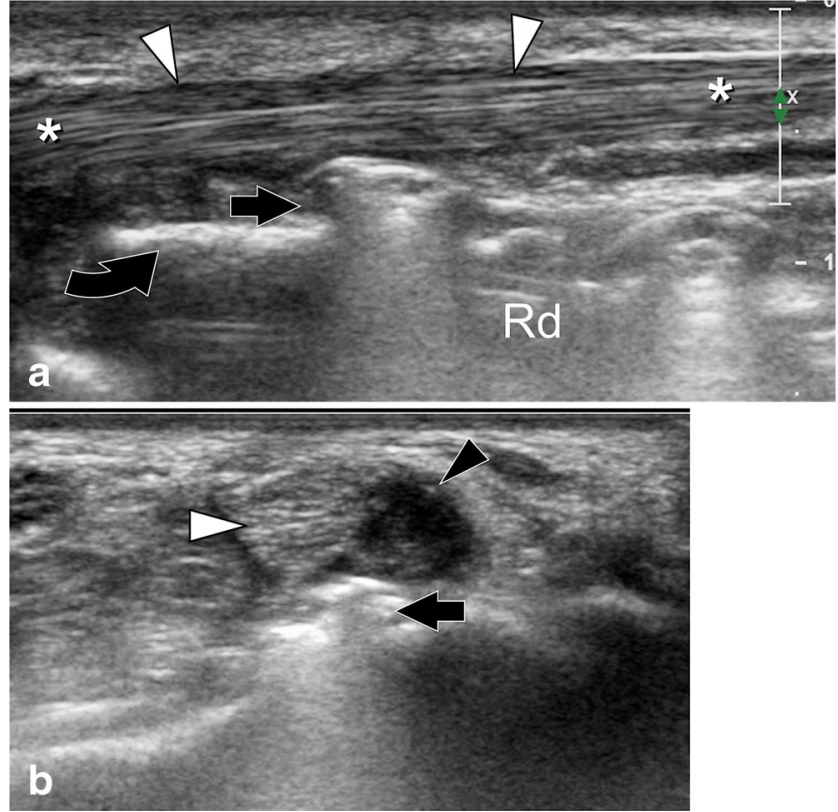

Fig. 27 Irritation by volar osteosynthesis plate of the radius causing tendinopathy and tenosynovitis. a-b Sagittal (a) and axial (b) US images show a focal, hypoechoic swelling of the FCRt (white arrowheads) associated with partial loss of the fibrillar pattern. The tendon, proximal, and distal $(*)$ to the pathologic segment is normal. In $\mathbf{b}$, note the associated effusion of the synovial sheath (black arrowhead). The pathologic changes are probably secondary to a local impingement of the tendon against the head of a screw (black arrows) of the osteosynthesis plate (black curved arrow). The screw and the osteosynthesis plate appear hyperechoic and present posterior artefacts (acoustic shadowing and reverberation). $R d$ radius

granuloma when chronic [27]. Abscesses are heterogenous, irregular, and hyperemic with color Doppler flow, whereas the granulomas are hypoechoic and non-hyperemic [24].

Bone avulsions of the distal insertion of the FCRt are rare and mainly seen in high-energy trauma (Fig. 25).

Iatrogenic tendinopathy and tears

The presence of a screw or osteosynthesis plate can irritate the FCRt and cause lesions ranging from tendinopathy or tenosynovitis (Figs. 26 and 27) to partial or even complete tears $[25,28]$. On US, screws appear as multiple parallel and oblique hyperechoic lines [28]. Osteosynthesis plates appear as elevated hyperechoic lines parallel to the adjacent cortical bone. Posterior acoustic shadowing and/or reverberation typically occur deep to metal screws or osteosynthesis plates. Sonopalpation and dynamic evaluation during wrist flexion/ extension can highlight the conflict between the tendon and hardware, in addition to reproducing symptoms. Color Doppler can show local hyperaemia, supporting the presence of local inflammation.

Tendon ruptures following trapeziectomy can be assessed by US (Fig. 28) as well as these due to corticosteroid
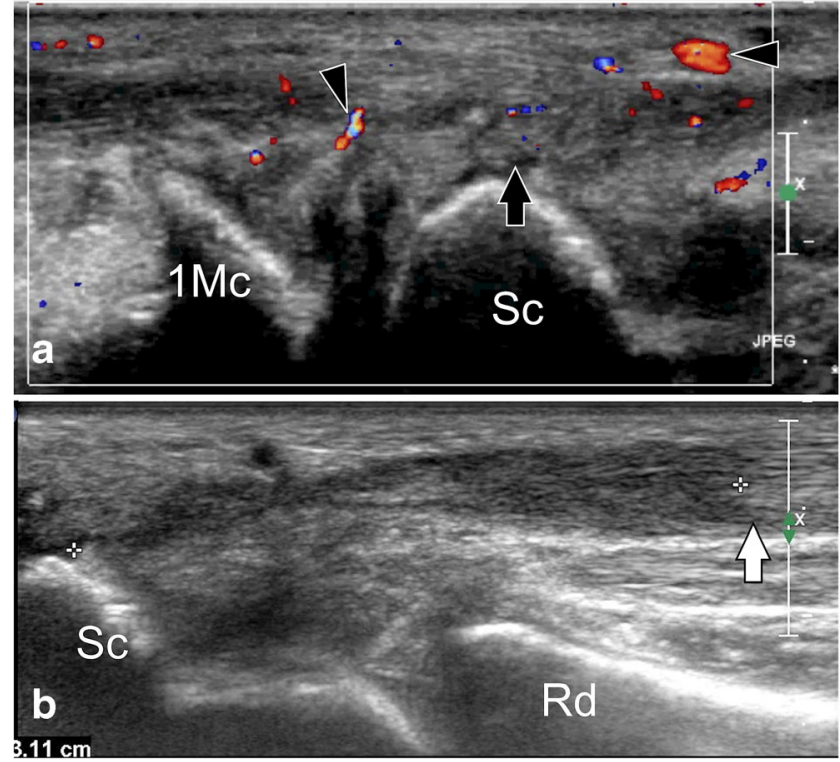

Fig. 28 Complete tendon tear in a patient who had a previous trapeziectomy. a Sagittal US image obtained over the palmar aspect of the STT joint complex showing the absence of the FCRt replaced by a local inflammatory process (black arrow) with local hyperemia (black arrowheads). The trapezium is also absent (post-trapeziectomy). The scaphoid (Sc) articulates with the first metacarpal (1Mc). b Sagittal US image obtained over the palmar aspect of the radius (Rd) shows the retracted proximal tendon stump (white arrow)

infiltrations. Risk factors include intratendinous steroid infiltration and/or significant tendinosis and partial thickness tearing. It should be noted that there might be normal or acquired communication between the STT joint and the FCRt synovial sheath, either on a congenital or degenerative basis [1]. If there is a communication, a steroid injection into the STT joint could diffuse to the FCRt sheath.

Cysts

FCRt synovial sheath cysts appear as a well-defined anechoic or hypoechoic masses, potentially accompanied by internal septa. The presence of a pedicle between the cyst and the synovial sheath confirms its origin. Coupled with color Doppler, US can show local hyperemia indicative of local inflammation (Figs. 29 and 30).

\section{Lesions to adjacent structures}

US allows easy identification of other pathology that may clinically mimic or occur concomitantly with FCRt disorders. In particular, lesions of the palmar cutaneous branch of the median nerve or pseudo aneurysm of the radial artery can mimic symptom of FCRt disorder [18, 29]. 
Fig. 29 Superficial peritendinous mucoid cyst. a-b Sagittal (a) and axial (b) US images obtained on the palmar aspect of the wrist. Images show a well-delimited, anechoic mass (black arrows, callipers in b) corresponding to a mucoid cyst located between the normal FCRt $(*)$ and the subcutaneous tissues. In a, the cyst shows a communication with the STT joint through a thin pedicle (black arrowheads). c Axial PD MR image of the wrist shows mild hyperintense signal of the cyst (black arrow). Note the normal FCRt (*). Sc scaphoid; $T r$ trapezium
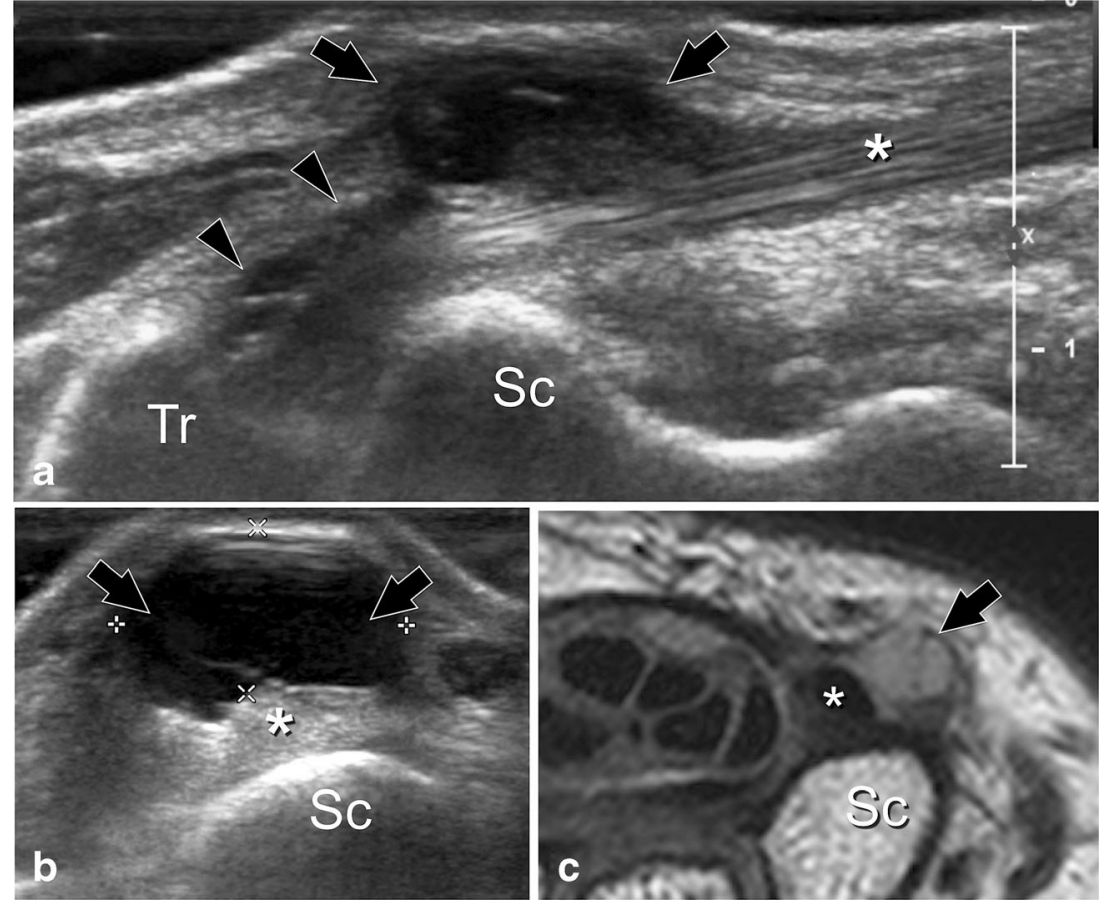

Possible preoperative assessment

Some surgeons partially or completely transect the FCRt when performing trapeziectomy for patients with 1 st carpo-

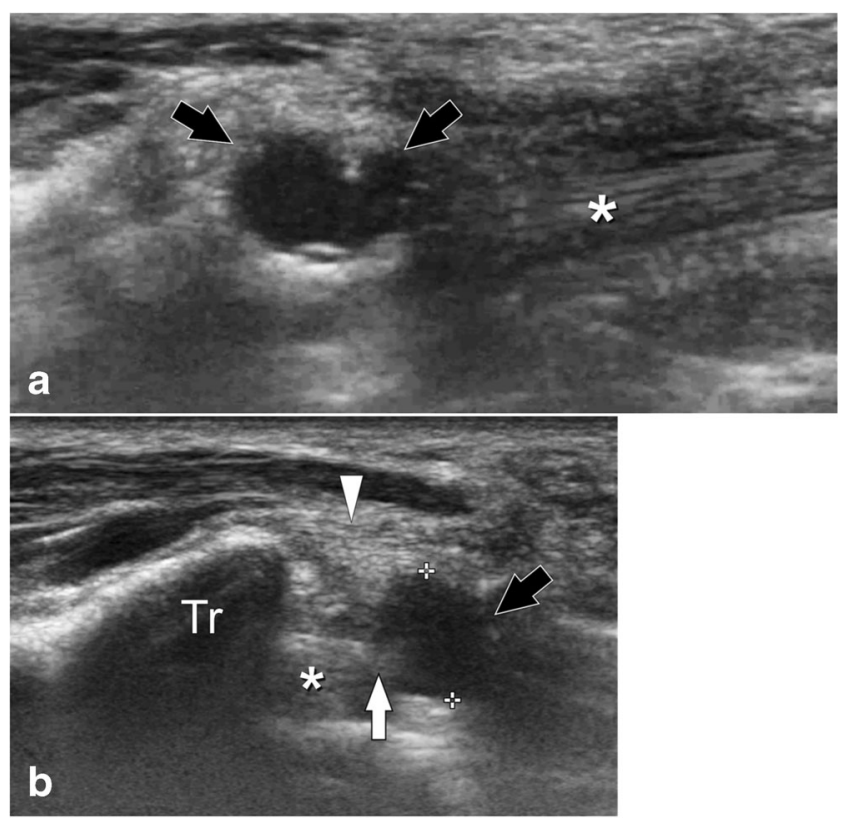

Fig. 30 Deep peritendinous mucoid cyst. a-b Sagittal (a) and axial (b) US images obtained on the palmar aspect of the wrist. Sonograms show an anechoic cystic lesion (black arrows, callipers in b) located under the flexors retinaculum (white arrowhead) in close relationship with the vertical retinacular septum (white arrow) and the normal FCRt (*). The cyst probably originates from the vertical retinacular septum. $\mathrm{Tr}$ trapezium metacarpal osteoarthritis. Depending on the extent of FCRt removal, the tendon may be used for ligamentous reconstruction about the joint, as well as to fill the empty space left by the trapeziectomy [1, 13, 30,31]. This ligament reconstruction tendon interposition technique depends on an intact distal attachment of the FCRt. In these cases, US can be used to evaluate the suitability of the FCRt as a graft in the pre-operative assessment. Alternative surgical techniques are available if whether the FCRt is partially or completely ruptured [31].

\section{Conclusions}

US and radiographs are complementary imaging modalities for assessment of volar radial wrist pain with suspected FCRt disorders. Radiographs enable panoramic evaluation of the wrist joints and bones, and may identify STT complex osteoarthritis - the most frequent cause of FCRt lesions. US permits accurate detection and grading of FCRt pathology. Dynamic imaging capabilities permit direct visualization of impingement by hardware or adjacent structures, and can facilitate differentiation of complete and partial tears. US evaluation of the FCRt should include adjacent structures as indicated to assist in the differential diagnosis and assess for associated lesions.

Conflict of interest The authors declare that they have no conflicts of interest. 


\section{References}

1. Parellada AJ, Morrison WB, Reiter SB, Carrino JA, Kloss LA, Glickman PL, et al. Flexor carpi radialis tendinopathy: spectrum of imaging findings and association with triscaphe arthritis. Skeletal Radiol. 2006;35(8):572-8.

2. Bishop AT, Gabel G, Carmichael SW. Flexor carpi radialis tendinitis. Part I: operative anatomy. J Bone Joint Surg Am. 1994;76(7):100914.

3. Ait Essi F, Younsi A, Abkari I, Benhima MA, Najeb Y, Latifi M, et al. Tumeur ténosynoviale à cellules géantes diffuse du poignet révélée par un syndrome du canal carpien : à propos d'un cas. Chir Main. 2012;31(5):256-8.

4. Hepper CT, Boyer M. Repair of flexor carpi radialis tendon laceration at the wrist in a professional ice hockey player. Orthopedics. 2011;34(6):225.

5. DiMatteo L, Wolf JM. Flexor carpi radialis tendon rupture as a complication of a closed distal radius fracture: a case report. J Hand Surg [Am]. 2007;32(6):818-20.

6. Tonkin MA, Stern HS. Spontaneous rupture of the flexor carpi radialis tendon. J Hand Surg (Br). 1991;16(1):72-4.

7. Gabel G, Bishop AT, Wood MB. Flexor carpi radialis tendinitis. Part II: results of operative treatment. J Bone Joint Surg Am. 1994;76(7): 1015-8.

8. McCann PA, Amirfeyz R, Wakeley C, Bhatia R. The volar anatomy of the distal radius - an MRI study of the FCR approach. Injury. 2010;41(10):1012-4.

9. Lantieri L, Hennebert H, Le Viet D, Guerin-Surville H. A study of the orientation of the fibers of the flexor carpi radialis tendon: anatomy and clinical applications. Surg Radiol Anat. 1993;15(2):85-9.

10. McCann PA, Clarke D, Amirfeyz R, Bhatia R. The cadaveric anatomy of the distal radius: implications for the use of volar plates. Ann R Coll Surg Engl. 2012;94(2):116-20.

11. Saulis AS, Sukkar SS, Dumanian GA. The distally based radial artery/flexor carpi radialis muscle flap for dorsal hand reconstruction: a clinical and cadaver study. J Hand Surg. 2002;27(6):1081-6.

12. Blair WF, Joos K. The innervation of flexor carpi radialis. An interfascicular dissection. Arch Neurol. 1982;39(10):647-9.

13. Naidu SH, Poole J, Horne A. Entire flexor carpi radialis tendon harvest for thumb carpometacarpal arthroplasty alters wrist kinetics. J Hand Surg [Am]. 2006;31(7):1171-5.

14. Salva-Coll G, Garcia-Elias M, Llusa-Perez M, Rodriguez-Baeza A. The role of the flexor carpi radialis muscle in scapholunate instability. J Hand Surg [Am]. 2011;36(1):31-6.

15. Peetrons P. Ultrasound of muscles. Eur Radiol. 2002;12(1):35-43.

16. Hsiao MY, Wang TG, Wu CH. Sonographic appearance of nontraumatic tear of flexor carpi radialis muscle-a case report. J Clin Ultrasound JCU. 2012.
17. Ho SY, Yeo CJ, Sebastin SJ, Tan TC, Lim AY. The flexor carpi radialis brevis muscle - an anomaly in forearm musculature: a review article. Hand Surg. 2011;16(3):245-9.

18. Tagliafico A, Pugliese F, Bianchi S, Bodner G, Padua L, Rubino M, et al. High-resolution sonography of the palmar cutaneous branch of the median nerve. AJR Am J Roentgenol. 2008;191(1):107-14.

19. Naredo E, D'Agostino MA, Wakefield RJ, Moller I, Balint PV, Filippucci E, et al. Reliability of a consensus-based ultrasound score for tenosynovitis in rheumatoid arthritis. Ann Rheum Dis. 2012.

20. Filippucci E, Gabba A, Di Geso L, Girolimetti R, Salaffi F, Grassi W. Hand tendon involvement in rheumatoid arthritis: an ultrasound study. Semin Arthritis Rheum. 2012;41(6):752-60.

21. Martinoli C, Bianchi S, Dahmane M, Pugliese F, Bianchi-Zamorani MP, Valle M. Ultrasound of tendons and nerves. Eur Radiol. 2002;12(1):44-55.

22. Chavez-Chiang NR, Sibbitt WL, Band PA, DeLea SL, Park KS, Bankhurst AD. The outcomes and cost-effectiveness of intraarticular injection of the rheumatoid knee. Rheumatol Int. 2012;32(2):513-8.

23. Sibbitt Jr WL, Peisajovich A, Michael AA, Park KS, Sibbitt RR, Band PA, et al. Does sonographic needle guidance affect the clinical outcome of intraarticular injections? J Rheumatol. 2009;36(9):1892-902.

24. Bianchi S, Della Santa D, Glauser T, Beaulieu JY, van Aaken J. Sonography of masses of the wrist and hand. AJR Am J Roentgenol. 2008;191(6):1767-75.

25. Soejima $\mathrm{O}$, Iida $\mathrm{H}$, Naito M. Flexor carpi radialis tendinitis caused by malunited trapezial ridge fracture in a professional baseball player. $\mathrm{J}$ Orthop Sci. 2002;7(1):151-3.

26. Ando A, Hatori M, Hagiwara Y, Isefuku S, Itoi E. Imaging features of foreign body granuloma in the lower extremities mimicking a soft tissue neoplasm. Ups J Med Sci. 2009;114(1):46-51.

27. Boyse TD, Fessell DP, Jacobson JA, Lin J, van Holsbeeck MT, Hayes $\mathrm{CW}$. US of soft-tissue foreign bodies and associated complications with surgical correlation. Radiographics: Rev Publ Radiol Soc N Am Inc. 2001;21(5):1251-6.

28. Bianchi S, van Aaken J, Glauser T, Martinoli C, Beaulieu JY, Della SD. Screw impingement on the extensor tendons in distal radius fractures treated by volar plating: sonographic appearance. AJR Am J Roentgenol. 2008;191(5):W199-203.

29. Henney SE, Bhattacharya V, Sarker BA. Iatrogenic pseudoaneurysm resulting in transection of the radial artery. J Ultrasound Med Off $\mathrm{J}$ Am Inst Ultrasound Med. 2004;23(8):1091-3.

30. Beall DP, Ritchie ER, Campbell SE, Tran HN, Ingari JV, Sanders TG, et al. Magnetic resonance imaging appearance of the flexor carpi radialis tendon after harvest in ligamentous reconstruction tendon interposition arthroplasty. Skeletal Radiol. 2006;35(3):144-8.

31. Jones Jr DB, Rhee PC, Shin AY, Kakar S. Salvage options for flexor carpi radialis tendon disruption during ligament reconstruction and tendon interposition or suspension arthroplasty of the trapeziometacarpal joint. J Hand Surg. 2013;38(9):1806-11. 